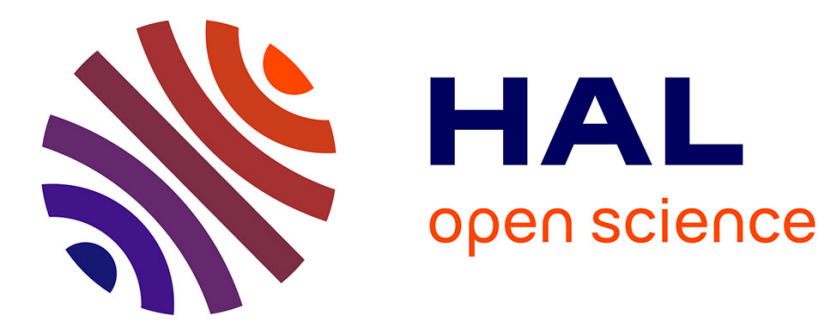

\title{
LE PROCÈS PONTIFICAL DE 1339 CONTRE L'ORDRE TEUTONIQUE
}

\author{
Sylvain Gouguenheim
}

\section{To cite this version:}

Sylvain Gouguenheim. LE PROCÈS PONTIFICAL DE 1339 CONTRE L'ORDRE TEUTONIQUE.

Revue historique, 2008. halshs-02426723

\section{HAL Id: halshs-02426723 \\ https://shs.hal.science/halshs-02426723}

Submitted on 30 Nov 2021

HAL is a multi-disciplinary open access archive for the deposit and dissemination of scientific research documents, whether they are published or not. The documents may come from teaching and research institutions in France or abroad, or from public or private research centers.
L'archive ouverte pluridisciplinaire HAL, est destinée au dépôt et à la diffusion de documents scientifiques de niveau recherche, publiés ou non, émanant des établissements d'enseignement et de recherche français ou étrangers, des laboratoires publics ou privés. 


\section{LE PROCES PONTIFICAL DE 1339 CONTRE L'ORDRE TEUTONIQUE}

Sylvain Gouguenheim, Professeur d'Histoire du Moyen Age, ENS-LSH de Lyon

Varsovie, 15 septembre 1339: l'Ordre teutonique est lourdement condamné à l'issue d'un procès conduit par des juges pontificaux. Il doit restituer à la Pologne plusieurs territoires récemment conquis comme le duché de Pomérélie ou obtenus en donation un siècle auparavant (le Culmerland, la terre de Dobrin). Si la sentence est appliquée, l'Ordre perdra environ un tiers de ses terres et verra sa puissance considérablement amoindrie. Comment en étaiton arrivé là ?

Créations originales du Moyen Age, enfants chéris de la Papauté, les ordres militaires connurent pourtant des périodes de disgrâce lors desquelles leurs adversaires firent valoir leurs critiques et arrivèrent parfois à leur porter de rudes coups. Au début du XIVe siècle, la chrétienté peinait à rassembler ses forces pour reprendre pied en Terre Sainte. Templiers et Hospitaliers étaient alors rendus responsables par certaines voix de la débâcle des Etats latins d'Orient. La montée en puissance des Etats européens et le renforcement de leurs appareils politique, militaire et judiciaire, ajoutés à la situation inconfortable d'une Papauté résidant en Avignon, rendaient par ailleurs fragile la position des ordres militaires. On connaît le célèbre procès qui mit fin aux Templiers (1307-1311) et qui démontrait qu'aucun ordre n'était à l'abri de l'anéantissement.

Quelques années plus tard, les Teutoniques, se trouvèrent à leur tour dans le collimateur de la Papauté. L'Ordre allemand en effet fut, à deux reprises (à Inowroclaw en 1320-1321 puis à Varsovie en 1339), traduit en justice à la demande de la royauté polonaise. On l'accusa dans un premier temps de s'être 
emparé illégalement du duché de Pomérélie en 1309. Puis, à la suite des guerres contre la Pologne lors des années 1326-1332, les charges se firent plus lourdes. Dans sa plainte portée auprès du pape en 1335 le roi Casimir III (1333-1370) dénonçait toute une série de crimes commis dans les territoires du nord de son royaume: églises et villages incendiés, populations massacrées, clercs mis à mort. Il réclamait toujours la restitution de la Pomérélie et, remontant dans le passé, il accusait en outre les Teutoniques de s'être illégalement installés sur les bords de la Vistule en 1230 et d'usurper le Culmerland, la terre de Dobrin (située au sud-est de Torun) et celle de Michelau au mépris du contenu des traités jadis conclus avec les princes de la famille des Piasts 1 . En bref, l'Ordre était à la fois accusé de crimes de guerre et de violation du droit international.

Lors du second procès le pape Benoît XII (1334-1342) se rangea sans ambages aux côtés du souverain polonais et menaça d'excommunication les Teutoniques, si du moins l'enquête révélait leur culpabilité. L'affaire était sérieuse et le souvenir de la dissolution du Temple - et de l'exécution d'un grand nombre de ses membres - pouvait planer de manière inquiétante audessus de Varsovie.

Le procès de 1339 a laissé une documentation complète qui permet d'aborder plusieurs aspects, politiques, judiciaires et mémoriaux. De façon à saisir tout l'intérêt de ce dossier, il importe de rappeler les événements qui servirent de prélude à l'intervention des juges.

\footnotetext{
Abréviations :

GSPK: Geheimes Staatsarchiv für Preussischer Kulturbesitz (Berlin-Dahlem).

Lites = Janina Zakrzewski, Lites ac Res Gestae inter Polonos Ordinemque Cruciferorum, 3 vol., Poznań, biblioteka Kórnicka (2 éd.), 1890-1935 ; t.1 : causam actam anno 1320 (p. 1-54); causam actam anno 1339 (p. 55-413).

Pmrl. UB = Pommerellisches Urkundenbuch (1140-1315), éd. Max Perlbach, Danzig, 1882.

Pr.UB = Preussisches Urkundenbuch, Bd. I/1 (1140-1257) éd. Rudolf Philippi/Carl-Peter Woelky, Königsberg, 1882 (réimpr. Aalen, 1961) ; Bd. III-1 (1335-1345), éd. Max Hein/Hans Koeppen, Königsberg/Marburg, 19441961.

UB Culm = Urkundenbuch des Bisthums Culm (Publicationen des westpreussischen Geschichstvereins. Neues preussisches Urkundenbuch. Westpreussischer Theil. Abth. III, Bd. I), éd. Carl-Peter Woelky, Danzig, 1884. Je remercie Claude Gauvard qui m'a fait part de plusieurs remarques et suggestions plus que judicieuses.

1 Etroite bande territoriale à la frontière du Culmerland et de la Masovie le long de la Drewenz, au sud de Strasbourg/Brodnica.
} 


\section{DU CHAMP DE BATAILLE AU TRIBUNAL (1308-1339)}

La prise de Dantzig le 13 novembre 1308 par les troupes de l'Ordre allemand fut suivie de l'annexion de l'ensemble du duché de Pomérélie en 1309. La principauté teutonique sur les rives de la Baltique s'accrut ainsi considérablement, et déplaça vers l'ouest son centre de gravité. L'Ordre proposa au souverain polonais Ladislas Lokietek (1320-1333) de lui acheter la Pomérélie, puis, devant son refus, s'adressa au margrave Waldemar de Brandebourg qui vendit le duché pour 10000 Marcs d'argent le 13 septembre 1309 (traité de Soldin²). Dans les jours qui suivirent (entre le 14 et le 21 septembre) eut lieu l'installation du grand maître Siegfried de Feuchtwangen à Marienbourg. La cité était située à proximité de la frontière orientale de la Pomérélie : en y plaçant son siège, Siegfried montrait que l'annexion de l'ancien duché était irréversible. Par ailleurs, en faisant sa résidence de ce qui n'était jusque là qu'une commanderie de faible importance, le grand maître signifiait que la Prusse devenait le centre des activités de l'Ordre, qui prenait ainsi définitivement congé de la Terre Sainte.

Dès lors les relations entre l'Ordre et la Pologne prirent un cours nouveau, beaucoup plus heurté. Au cours du XIIIe siècle, la branche prussienne de l'Ordre allemand avait représenté une force auxiliaire, dont la puissance dirigée contre les païens de Prusse et de Lituanie servait les intérêts de la Pologne. Au contraire, à partir de 1310, les Polonais, dont le royaume divisé venait d'être amputé du duché de Dantzig, se sentirent menacés par «l'Ordensstaat»en construction, qui s'affirmait comme un voisin puissant, voire un rival menaçant. La frontière entre l'État teutonique et la Pologne courait désormais le long de la Pomérélie, de la Masovie et de la Cujavie ${ }^{3}$. Les chicanes territoriales,

\footnotetext{
2 Pmrl. UB, no 676.

3 Ce duché, situé à l'ouest de la Masovie et au sud-ouest du Culmerland, englobait notamment les villes de
} 
nombreuses au XIII $\mathrm{e}^{\mathrm{e}}$ siècle, revêtirent un aspect plus conflictuel. Malgré la volonté commune de lutter contre la Lituanie, la Pologne ne pouvait plus considérer son voisin comme un partenaire amical. Le rétablissement de la domination polonaise sur la Pomérélie fut l'un des objectifs des deux rois successifs Ladislas Lokietek et Casimir III, même s'il serait erroné de penser que leur politique étrangère se limitait à cette récupération. La Pologne avait en effet d'autres voisins que les Teutoniques et d'autres ambitions territoriales, en particulier en direction de l'est et du sud-est. En raison de l'intensité du conflit contre l'Ordre, on oublie souvent ce point, mais les cent années qui séparent la prise de Dantzig de la bataille de Tannenberg en 1410 ne doivent pas être lues comme un long prélude à l'affrontement final. De même les clauses des traités de paix de 1411 et 1466 ne correspondent pas non plus à des objectifs poursuivis sans interruption par les Polonais depuis 1309-13104.

Les Polonais, qui renâclaient à payer le denier de Saint-Pierre, s'efforcèrent dès le règne de Ladislas Lokietek de détourner la colère pontificale en soulignant que, depuis sa prise en main par les Teutoniques, la Pomérélie ne s'en acquittait plus, de même d'ailleurs que le Culmerland puisque l'Ordre en était exempté. Un lien était ainsi établi entre un problème politique et territorial, auquel la Papauté était étrangère, et un litige fiscal dont l'enjeu était, pour les papes d'Avignon, de première importance. L'opposition entre les papes et l'Empereur Louis de Bavière (1314-1347), proche des Teutoniques, était un motif supplémentaire de l'intervention pontificale.

A l'issue du premier procès, le 10 février 1321, les juges condamnèrent l'Ordre à restituer le duché de Pomérélie à la Pologne, ainsi qu'à verser 30000 Marcs de dédommagement. Le jugement fut sans effet: les juges étaient des ecclésiastiques polonais et l'Ordre fit appel le même jour. Jean XXII refusa de se

Leslau, Brest, Inowroclaw, Kruschwitz, et Bromberg.

4 Voir les remarques en ce sens de Hartmut Boockmann, Der Deutsche Orden. 12 Kapitel aus seiner Geschichte, Munich, Beck, 1982. 
prononcer et la condamnation demeura lettre morte jusqu'à son annulation en 1332.

Il s'ensuivit une période où alternèrent paix armée, affrontements sporadiques et véritables campagnes militaires. Celles-ci, notamment entre 1326 et 1332 , provoquèrent de multiples ravages dont les sources des deux camps se firent l'écho ${ }^{5}$. Ladislas Lokietek et la noblesse polonaise voulaient reprendre le contrôle de la Pomérélie et, fait nouveau, remettaient en cause la donation du Culmerland à l'Ordre - effectuée par le duc Conrad de Masovie en 1230 - en avançant qu'elle n'avait plus de raison d'être puisque la christianisation de la région était achevée.

Les affrontements furent interrompus grâce à l'entremise du légat pontifical Pierre d'Auvergne (également collecteur du denier de Saint-Pierre en Pologne), qui imposa un armistice valable jusqu'au printemps 1333. Après de longues négociations, celui-ci fut prolongé jusqu'au 24 juin 1335 par un accord entre le grand maître Luther de Brunswick et Casimir III le 30 avril 13346.

Casimir III porta de nouveau plainte auprès du pape en 1335. Réclamant le retour à la couronne polonaise de l'ensemble des terres contestées, il dénonçait en outre les crimes et les actes de violence perpétrés par les Teutoniques entre 1326 et 1332. Casimir III entendait donc placer l'offensive sur le terrain du droit, du respect des traités et des normes de la guerre juste.

Benoît XII diligenta une enquête informative, conduite par deux cardinaux: Pierre, Cardinal-prêtre au titre de Sainte-Praxède, et Jean Orsini, Cardinal-diacre de Saint-Théodore. Au même moment, des négociations internationales avaient lieu et, sous les auspices de Charles IV de Hongrie et

\footnotetext{
5 Après l'armistice de Lęczyca (février 1326), de courte durée, les combats reprirent et dès 1327 l'Ordre pénétra en Cujavie. Allié à Jean de Luxembourg roi de Bohême, il occupa notamment la terre de Dobrin en 1329 tandis que Ladislas Lokietek répliquait en dévastant le Culmerland. Les Teutoniques menèrent en 1331 des campagnes destructrices en Grande Pologne et dans les terres de Sieradz et de Lęczyca, assiégeant même en septembre les villes de Poznan et de Kalisch. Ils subirent toutefois une importante défaite à la bataille de Plowce le 27 septembre 1331. D'autres combats violents eurent lieu en 1332 Cujavie et dans la terre de Michelau.

6 Pr. UB, II, n 837.
} 
Jean de Bohême, un arbitrage fut rendu à Visegrad le 26 novembre 1335, aux termes duquel Casimir renonçait à la Pomérélie; les Teutoniques pourraient conserver sans être inquiétés la terre de Culm ainsi que la partie de la Cujavie et de la terre de Dobrin qu'ils contrôlaient avant la guerre ${ }^{7}$. L'arbitrage fut accepté par le grand maître Dietrich d'Altenbourg en janvier 1336, et, bien que la sentence ne lui fut pas favorable, Casimir le Grand s'y plia néanmoins le 26 mai 1336, mais en limitant à une année (soit la durée d'un armistice) son application 8 ...

Le souverain polonais tenta alors d'arriver à ses fins au moyen d'une double politique : il renégocia directement avec l'Ordre en 1337 et, parallèlement, demanda à la Papauté, via l'archevêque Ianislas de Gniezno et Jean de Lodz évêque de Poznan, qu'un nouveau procès soit instruit. D'une manière ou d'une autre, dans les deux cas par un moyen pacifique, il espérait ainsi l'emporter. Après la mort de Jean de Saint-Théodore (27 août 1335) et alors que Pierre de Sainte-Praxède était retenu par d'autres affaires, le Cardinal Jean, évêque de Porto, présenta devant la Curie les conclusions de l'enquête sur les différents chefs d'accusation. Elles furent alors mises par écrit et c'est en s'appuyant sur ce rapport, comme sur la déposition faite devant lui par l'archevêque Ianislas, que, le 4 mai 1338, Benoît XII chargea deux collecteurs pontificaux, Pierre Gervais et Galhard de Carcès de procéder à un interrogatoire de témoins et à un jugement 9 .

Le procès s'ouvrit le 4 février 1339 à Varsovie et dura jusqu'au 15 septembre. L'instruction offre matière à de passionnants témoignages. Juridiquement la cause n'est pas aisée à trancher car l'Ordre et la Pologne avaient

\footnotetext{
7 Pr.UB, III-1, n 32; GSPK, XXe Abt., Pg. Uk. Sch. 109, nº 39 (A).

8 Pr.UB, III- $1, \mathrm{n}^{\circ} 40$ et 64.

9 Galhard de Carcès (dépt. Tarn-et-Garonne, arr.Moissac, cant. et comm. Lauzerte) fut nommé en 1334, à la place du légat Pierre d'Auvergne, et occupa cette fonction jusqu'en 1341; le 23 mai 1336 la Papauté nomma pour l'épauler Pierre Gervais, chanoine du Puy. Sur ce dernier voir Elisabeth Mornet, Le chanoine Pierre Gervais, nonce et collecteur pontifical. Jalons pour une biographie, dans Finances, pouvoirs et mémoire. Hommages à Jean Favier, Jean Kerhervé et Albert Rigaudière éd., Paris, Fayard, 1999, p. 565-577.
} 
tous les deux des droits sur la Pomérélie, à la suite des inféodations successives de la fin du XIIIe siècle - dont l'histoire est complexe à souhait et ornée de multiples rebondissements. Le cas du Culmerland donna lieu de son côté à des accusations d'usurpation dont les diplômes aujourd'hui conservés ne confirment pas la légitimité. A propos du denier de saint Pierre la situation n'est pas non plus nette, en particulier pour le Culmerland. La région dépendait à l'origine du diocèse de Plock, donc de la province de Gniezno. Puis la terre passa à l'évêque missionnaire Christian en 1215. Devenu évêché autonome 1243, elle dépendait de la métropole de Riga lorsque l'archevêché fut institué en 1245. Arguant du fait que le Culmerland en tant que diocèse n'avait jamais relevé de l'Eglise polonaise, les évêques de Culm refusaient de payer le denier de Saint-Pierre10. Des bulles de Jean XXII en 1317 et 1318 affirmaient pourtant l'appartenance du Culmerland à la province de Gniezno, afin d'obtenir le versement désiré... L'Ordre fit appel de sa condamnation et le Pape renonça, sous sa pression, à promulguer la sentence finale. L'action de la justice pontificale n'avait donc en rien modifié la situation.

Le dossier des actes du procès est d'une exceptionnelle richesse et on ne peut se passer, pour en appréhender les aspects juridiques, historiques ou ceux relatifs à la tradition manuscrite, de la magistrale étude d'Helena Chłopocka11. Je me limiterai ici à présenter des remarques sur trois points : l'usage que l'on fit des actes du procès, le déroulement de ce dernier, enfin la manière dont les témoins auditionnés se représentaient un événement vieux d'un siècle, en l'occurrence la donation du Culmerland aux Teutoniques. Le débat juridique permet d'étudier la mémoire d'un événement conflictuel en comparant les assertions des témoins avec les pièces documentaires demeurées en notre

\footnotetext{
10 UB Culm, $\mathrm{n}^{\circ} 176$.

11 Helena Chłopocka, Procesy Polski z zakonem krzyżackim w XIV wieku. Studium źródłoznawoze, Poznan, 1967, 255 p. Dans sa première partie largement consacrée aux précédents historiques (procès de 1311-1312 et 1320-1321) H. Chlopocka s'est intéressée aux aspects proprement judiciaires : étapes et contenu de la procédure, fondements canoniques du procès (elle a recherché minutieusement les noms et les œuvres des décrétistes et décrétalistes susceptibles d'éclairer l'ensemble des aspects juridiques).
} 
possession. On verra ainsi comment la mémoire collective - du moins celle d'une partie des élites - a contribué à créer en la personne des Teutoniques une figure négative, nécessaire à la formation de la conscience nationale polonaise.

\section{LA SOURCE ET SES USAGES}

Les actes complets du procès figurent aujourd'hui dans un unique manuscrit, conservé à la bibliothèque de l'Académie des Sciences de Kórnik, à une vingtaine de $\mathrm{km}$ de Poznan 12.

\section{Le manuscrit et son histoire}

Le destin du manuscrit original du procès est inconnu : il fut sans doute emporté avec lui par son rédacteur, Pierre de Montiglio, chanoine du Puy, qui était le principal notaire en fonction lors du procès. On a néanmoins conservé une transcription de la main d'Adalbert «fils de Christian», un chanoine de Cracovie, qui exerçait la fonction de connotarius et confectionna sa copie à partir de l'original, juste après l'énoncé de la sentence finale13. Effectuée avec

\footnotetext{
$12 \mathrm{BK}, \mathrm{n}^{\circ}$ 155, $91 \mathrm{f}^{\circ}$. Edition Janina Zakrzewski, Lites ac res gestae inter Polonos ordinemque Cruciferorum, t. I, Poznan, 1890, 461 p. Pour le premier procès il convient de se reporter à l'édition d'Helena Chlopocka, Lites ac res gestae inter Polonos ordinemque Cruciferorum, Varsovie, 1970, 134 p. Il existe aussi certaines pièces en original à Berlin, par exemple la sentence finale du procès (GSPK, XXe Abt., Pg. Uk., Sch. 109, n 44) ou la contestation de la légitimité des juges pontificaux Galhard de Carcès et de Pierre Gervais par les Teutoniques (GSPK, XXe Abt., Pg. Uk., Sch. 60, $\mathrm{n}^{\circ} 21 \mathrm{~b}$ ); Hubert Hubatsch signale en outre un exemplaire de la sentence, disparu (Regesta historico-diplomatica Ordinis S. Marie Theutonicorum, Pars I, Regesten zum Ordensbriefarchiv,p. 12, n 206a). L'exemplaire de la sentence finale destiné à la cour de Pologne n'a pas été conservé.

13 La relation par Adalbert de sa propre copie conclut le manuscrit : « Et moi Adalbert fils de Christian, clerc du diocèse de Cracovie, notaire public par autorité apostolique et impériale, avec maitre Pierre de Montiglio conotaire de la présence affaire indiqué ci-dessous, tels que je les ai trouvés dans le registre écrit de la main de ce même maitre Pierre, j'ai fidèlement transcris tous les actes, un par un, tels qu'ils furent enregistrés ; je les ai fidèlement recopiés dans les quatre-vingt-neuf folios de parchemin ici présents, n'ajoutant ni n'ôtant rien qui modifie le sens ou altère l'esprit, et avec le même maitre Pierre, j'ai examiné attentivement le registre original. J'ai rédigé ce document public sur ordre des dits seigneurs juges et j'ai, à leur demande, signé aux $10^{\circ}, 20^{\circ}, 30^{\circ}$, $40^{\mathrm{e}}, 50^{\mathrm{e}}, 60^{\mathrm{e}}, 70^{\mathrm{e}}, 82^{\mathrm{e}}$ et $89^{\mathrm{e}}$ folios des dits folios de parchemin....», (Lites, op. cit, t. I, p. 407-408). Comme le procureur de l'Ordre n'avait pas exigé d'exemplaire des actes, aucune copie ne fut préparée à son intention; les Teutoniques n'eurent donc jamais à leur disposition une version complète des actes du procès. Seul un
} 
un grand soin sur parchemin (même si elle n'est pas exempte de quelques défauts ${ }^{14}$ ), elle est accréditée par la souscription et l'apposition du seing notarial de Pierre de Montiglio, qui confirme que le texte en a été fidèlement transcrit à partir de son propre registre 15 .

Cette copie fut vraisemblablement très vite entreposée dans les archives royales à Cracovie. L'historien Jan Dlugosz (1415-1480) la fit restaurer puis redéposer dans ces mêmes archives, le 12 juin 1479 ; l'épisode est relaté dans le folio de garde du manuscrit 16 . L'expression de « livre assurément utile et nécessaire au royaume » par laquelle commence le texte, et que l'on doit à Jan Dlugosz, montre la valeur encore attribuée à ces actes, alors que la Pologne semblait avoir définitivement abattu la puissance de l'Ordre depuis la deuxième paix de Thorn de 146617 .

Au milieu du XVIe siècle le manuscrit fut prêté par la couronne de Pologne à l'ancien grand maître de 1'Ordre teutonique, Albert de Hohenzollern qui souhaitait en disposer afin d'améliorer le contenu d'une Chronique de Prusse dont il avait commandé la réalisation. Le codex fut recopié par un membre

exemplaire de la sentence fut enregistré dans les archives centrales de l'Ordre (GSPK, XXe Abt., Pg. Uk., Sch. 109, $\left.\mathrm{n}^{\circ} 44\right)$.

14 Janina Zakrzewski, Lites..., t. I, p. 63.

15 «Et moi Pierre de Montiglio (...) je fus présent en personne et j'ai couché par écrit dans mon registre toutes ces choses, une à une, et ayant fait avec diligence la collation de ce registre composé de ces 89 folios, et l'ayant rédigé sous la forme d'un instrument public, avec le notaire public susdit et conotaire de cette affaire, après avoir constaté que tout concordait, j'ai signé ici et j'ai apposé mon seing habituel. » (Lites, t. I, p. 408).

16 «Livre et registre du royaume et du roi de Pologne, assurément utile et nécessaire au royaume de Pologne, qui contient les dépositions et les attestations d'excellentes et insignes personnes, des plus grands sans exceptions, déclarant et prouvant que les terres de Poméranie, Culm et Michelau font partie et relèvent, doivent faire partie et relever de la propriété, du droit et du corps du royaume de Pologne. Il contient aussi la sentence finale prononcée en justice par les juges apostoliques, Galhard de Carcès prévôt du diocèse de Kalocsa et Pierre Gervais chanoine du Puy, délégués spéciaux du pape Benoît XII. Cette sentence n'est sous le coup d'aucun appel, elle a l'effet d'un jugement définitif, elle adjuge et attribue les dites terres au roi et au royaume de Pologne, les en fait les propriétaires, et déclare que le maître et l'Ordre de Prusse n'ont ni ne peuvent avoir aucun droit sur ces dites terres. Moi, Jan Dlugosz l'ancien, chanoine de Cracovie, j'ai refait et restauré ce registre et je l'ai replacé dans les archives royales de Cracovie en l'an du Seigneur 1479, à la douzième lune du mois de Juillet. », Lites, t. I, p. 63 ; reproduction du folio in Helena Chłopocka, Procesy..., op. cit., p.116).

17 Liber et regestrum regni et Regis Polonie valde utile et necessarium Regno... ; Helena Chłopocka, O protokołach procesów polsko-krzyżackich w XIV i XV wieku, dans Venerabiles, nobiles et honesti, Studia z dziejów spoleczeństwa Polski średniowiecnej, Andrzej Radziminski, Anna Supruniuk et Jan Wroniszewski éd., Toruń, 1997, p. 421-431, ici p. 425. Jan Dlugosz donne par ailleurs des versions résumées des deux sentences dans ses Annales. 
inconnu de sa chancellerie, dans la période du $1^{\text {er }}$ septembre 1549 au 5 mars 1550, avant d'être restitué à la Pologne18. Il n'y a pas de raison de douter qu'elle fut alors remise à sa place dans les archives royales 19 . Le manuscrit aurait ensuite quitté Cracovie en 1551-1552 au plus tard, pour être déposé dans les archives familiales de Jakob Ostrorog, percepteur des impôts de la voïvodie de Poznan puis futur staroste général de Grande Pologne en 156620. En 1564 Jakob Ostrorog, en possession d'une cassette renfermant vingt-trois documents et deux manuscrits concernant les procès entre l'Ordre et la Pologne, déposa ces textes à l'hôtel de ville de Poznan, sans que l'on sache très bien s'il les destinait à un usage immédiat, d'ordre politique par exemple, ou s'ils étaient déjà considérés comme des documents dépassés. Le manuscrit du procès intégra ensuite la bibliothèque du château de Kórnick.

\section{Richesse du contenu}

Les actes englobent au total quarante-quatre documents notariés, qui couvrent l'intégralité des acta processus 21 . On trouve donc la présentation des témoins, les citations à comparaître, la présentation des instruments publics et celle des procureurs du roi de Pologne, la bulle de Benoît XII du 4 mai 1338 dépêchant ses deux enquêteurs en Pologne à la suite de la plainte de Casimir III. Suivent plusieurs citations à comparaître adressées à l'Ordre entre le 15 novembre et le 20 décembre 1338 en raison de son refus de venir devant les juges (la procédure applicable en cas de contumace est suivie à la lettre). Viennent ensuite la pétition du roi de Pologne (Petitio summaria procuratoris

\footnotetext{
18 GSPK, XXe Abt., OF, n 290.

19 Helena Chłopocka, O protokołach..., p. 426.

20 S'il figure encore dans un inventaire de 1532 il n'est plus signalé dans ceux de 1551, 1569-1572, 1613, 1622 ;

H. Chłopocka indique l'année 1552 comme terminus post quem tout en signalant l'absence dans l'inventaire de 1551 (Procesy..., p. 188 et 192).

21 Figure parmi ces documents une copie authentifiée du jugement du 10 février 1321 qui servit de preuve (Lites, t. I, p.123-124).
} 
regis Polonie), la présentation des procureurs de l'Ordre, l'Assignatio loci judicii, la protestation de l'Ordre et son appel (qui mêle diverses accusations contre Casimir à un vif éloge de l'héroïsme des Teutoniques). Suivent alors les trente articuli, qui représentent le contenu précis de la plainte (chefs d'accusation ou sujets d'enquête). Enfin sont consignées la production des témoins et leurs prestations de serment. Les cent-vingt-six témoignages enregistrés constituent le fonds du procès, les acta causae, et forment un appendice autonome qui couvre les folios $24 \mathrm{v}-89^{22}$. Après l'énoncé de la sentence finale et de l'appel de l'Ordre contre elle, marques et formules de souscription des notaires concluent le manuscrit.

Bref l'historien est en présence d'un dossier complet, fort riche, et qui offre matière à un grand nombre d'investigations. L'ensemble ne se distingue pas de manière radicale de l'enregistrement des actes du procès de 1321 mais les techniques notariales y sont bien mieux maittrisées. Ces actes furent considérés comme une formidable pièce à conviction, encore utilisée lors du traité de Versailles en 1919 par la délégation polonaise 23!

\section{DEROULEMENT D'UN PROCES A CHARGE}

Le procès s'ouvrit sous la présidence des deux juges pontificaux, Galhard de Carcès et Pierre Gervais qui, depuis 1334, exerçaient la fonction de collecteurs du denier de saint Pierre en Pologne et Hongrie et étaient entièrement favorables à la cause polonaise. Ils voyaient le plus grand intérêt à ce que les terres contestées reviennent à la Pologne car elles payeraient le denier de Saint-

\footnotetext{
22 Soit plus de 250 pages dans l'édition de Janina Zakrzewska (Lites, op. cit., p. 143-407).

23 Le représentant polonais aux délibérations du Conseil des Quatre (mars-juin 1919), J. Paderewski, rappelait la cruauté de l'Ordre teutonique pour justifier la méfiance de la Pologne envers les garanties que l'Allemagne pouvait proposer : « Je pourrais vous rappeler l'histoire de ce grand maître de l'Ordre teutonique qui, ayant signé un traité avec plusieurs des princes poméraniens et polonais de la région côtière, les invita tous à un banquet pendant lequel il les fit assassiner », cité par Paul Mantoux, Les délibérations du Conseil des Quatre, vol. 1, Paris, 1955, p. 201-202.
} 
Pierre, tandis que les Teutoniques, et avec eux le parti impérial, s'en trouveraient affaiblis. Inlassablement, ils ne cessèrent donc de demander aux témoins si les territoires contestés avaient à un moment ou à un autre acquitté le denier de Saint-Pierre.

\section{Les conditions du procès : le parti pris des enquêteurs pontificaux}

Leur rapport en date du 10 juillet 1337 montre combien les deux nonces tenaient en mauvaise estime les Teutoniques. Traitant des terres soumises à la domination de l'Ordre, Galhard de Carcès et Pierre Gervais signalent qu'elles ne payent pas le denier de Saint-Pierre et affirment au passage qu'elles relèvent en fait du royaume de Pologne 24 . Ils ajoutent que les droits du siège pontifical y sont bafoués 25 et achèvent leur rapport par une phrase extrêmement dure: l'attitude de l'Ordre et celle de la Pologne envers la Papauté diffèrent comme l'ombre et la lumière. Tandis que la Pologne est la servante de Rome, l'Ordre prétend en être le maître...26. Il est plus que probable que ce texte renforça l'engagement de la Papauté en faveur de la Pologne.

C'est donc à des nonces hostiles aux Teutoniques que parvint la lettre de Benoît XII du 4 mai 1338, adressée à la fois au roi de Pologne et à l'archevêque de Gniezno 27. Evoquant la plainte de Casimir III à l'origine du procès, le pape rappelait l'ampleur et la nature des crimes commis par les Teutoniques, que l'enquête de Jean de Saint Théodore et de Pierre de Sainte Praxède avait

\footnotetext{
$24 \operatorname{Pr}$. UB, III-1, n 119 ; (ASV, Instrum. Miscell. Caps. 209 n²).

25 Item sciat vestra sanctitas, quod in omnibus civitatibus regni Polonie, in quibus Theutonici dominantur, omnia iura sedis apostolice et vestre camere quasi depereunt in totum (Pr.UB, III-1, $\mathrm{n}^{\circ} 119$ ).

26 Placeat vestre sanctitati in dignitatibus istarum parcium conferendis ponderare fidelitatem, devocionem et utilitatem, quam vestra camera habet a Polonis, et devocionem et utilitatem, quam habet a Theutonicis vel Bohemis. Nam tanta est differencia sicut lucis ad tenebras, nam isti dicunt et recognoscunt sanctam Romanam matrem ecclesiam eis debere dominari, illi autem asserunt eisdem debere ancillari et esse sub tributo...(ibid.).

27 Lites, t. I, p. 68-71;Pr.UB, III-1, $\mathrm{n}^{\circ}$ 157. Une copie figure dans les Registres avignonnais conservés aux archives du Vatican (Reg. Vat. $125, \mathrm{n}^{\circ} 340, \mathrm{f}^{\circ} 117 \mathrm{v}-118 \mathrm{v}$ pour la lettre à Casimir III et $\mathrm{f}^{\circ} 118 \mathrm{v}-119$ pour celle expédié à l'archevêque Ianislas); deux autres, datant du XVe siècle, figurent au sein des archives de l'Ordre (GSPK, XXe Abt., OBA, nº 111 et OF, 12, fo 241v et 290).
} 
établies. Il chargeait Pierre Gervais et Galhard de Carcès d'enquêter au sujet de ces actes de violence, ut complementum iustitiae faciant. Parmi les crimes dont les Teutoniques étaient accusés figuraient, outre l'usurpation de terres appartenant au royaume de Pologne, de nombreux sacrilèges commis aux dépens des édifices religieux, des cités ou des forteresses : incendies de près de cent églises, vols, meurtres et viols (res sacras rapiendo, ecclesias concremando, personas occidendo et virgines violando). La lettre ne précisait rien au sujet de la procédure à suivre, parfaitement connue des deux juges. Benoît XII reprenait intégralement le texte de son prédécesseur Jean XXII qui, le 23 mars 1331, dans une lettre adressée à l'archevêque de Gniezno et aux évêques de Cracovie et de Poznan, déclencha une enquête au sujet des violences commises dans l'évêché de Leslau par le grand maître, le commandeur du bailliage de Culm et les commandeurs de Gollub, Schwetz et Engelsburg 28 . Le texte de Jean XXII détaillait l'ensemble des crimes et lançait l'excommunication contre les incendiaires d'églises. Le pape y expliquait la conduite à tenir si les membres de l'Ordre refusaient de comparaître ou s'opposaient, en s'appuyant sur leurs privilèges d'exemption, aux sanctions d'excommunication ou d'interdit.

Benoît XII rappelait ensuite les résultats de l'enquête informative sur l'infamia de l'Ordre, qui avaient été présentés devant la Curie par Jean de Porto, couchés par écrit et enregistrés 29 . L'infamia étant établie, le pape exigeait que

$28 \operatorname{Pr} . U B, \mathrm{II}, \mathrm{n}^{\circ} 730$, p. 479-482, ici p. 481 de la ligne 14 à la fin.

29 «Le dit roi nous ayant supplié d'intervenir et de remédier de manière opportune au sujet de cette affaire, et voulant que le siège apostolique sache si le maître et les dits frères avaient agi en l'occurrence en infamie (an magister et fratres predicti super premissis infamia laborarent), nous avons chargé, oralement et de vive voix, nos chers fils les cardinaux Pierre prêtre au titre de Sainte-Praxède et Jean diacre de Saint-Théodore de bonne mémoire, alors encore en vie, d'informer pleinement le siège apostolique au sujet de cette affaire et de nous faire un rapport de ce qu'ils auraient trouvé à la suite de leur enquête. Ensuite, ayant été informé par eux de l'infamie existante (super huiusmodi infamia informacione recepta), et comme le dit Jean, ainsi qu'il l'a plu à Dieu, avait été soustrait de cette lumière, et que le Cardinal Pierre, par mandat spécial de notre part était absent de la curie romaine pour traiter de délicates affaires, notre vénérable frère Jean évêque de Porto reçut mandat spécial de notre part, par oral et de vive voix. Après avoir pris connaissance de l'enquête des dits cardinaux, dont nous avions fait consigner par écrit les actes, il fit en consistoire, en notre présence et celle de nos frères, une relation entière et fidèle de l'affaire » (Lites, t. I, p. 68-69). 
les Teutoniques restituent entièrement les terres usurpées - y compris le Culmerland - et dédommagent la Pologne pour les dégâts subis 30 .

Les conditions étaient réunies pour que s'ouvre un procès ex officio où les juges enqueteraient sur la fama entourant les actions de l'Ordre. La sentence finale rappelait de nouveau que tout avait été fait dans les règles, en récapitulant l'ensemble des étapes parcourues 31 . Finalement l'Ordre fut condamné le 15 septembre 1339, par contumace puisque ses représentants étaient toujours absents 32 . Ils s'en justifièrent en déclarant que la route menant de Prusse en Pologne était trop dangereuse...

\section{La défense de l'Ordre}

Cette situation explique certainement le système de défense adopté par l'Ordre, qui semble a priori peu efficace mais qui était en réalité l'unique voie possible. Les Teutoniques demandèrent l'appui du pouvoir impérial et choisirent par ailleurs de ne pas répondre aux convocations (tactique de la contumace), tout en interjetant appel auprès du pape. Il faut y voir moins une dérobade que le recours assez judicieux à de réelles solutions juridiques.

Le 22 juillet 1338 l'empereur Louis de Bavière interdit aux Teutoniques de se présenter devant le tribunal de Varsovie 33 . L'Ordre put ainsi s'abriter derrière un solide paravent, et arguer du fait qu'il lui était impossible de désobéir à l'Empereur, d'autant que celui-ci le présentait comme relevant entièrement de sa juridiction. On sait que tel n'était pas le cas, puisque, comme tout ordre

\footnotetext{
30 Et quia per relacionem huiusmodi nobis constat, quod magister et fratres predicti super premissis noscuntur infamia laborare...ibid.

31 Sont mentionnés la réception de la peticio, les serments de dire la vérité, la contumace de l'Ordre allemand, la production des articles accusatoires et des témoins, l'examen des témoins, l'enregistrement de leurs dépositions, l'examen des dépositions et des preuves, l'énoncé de la sentence prononcé devant les Evangiles de sorte que «le jugement soit prononcé en face de Dieu »... (Lites, t. I, p. 134).

32 Pr.UB, III-1, n 271 ; original : GSPK, XXe Abt., Pg. Uk., Sch. 109, n 44: instrument notarié avec les sceaux de Pierre Gervais et Galhard de Carcès.

33 Pr.UB, III-1, n 183 ; original : GSKP Pg.Uk., Sch. 109, nº 43 (sceau impérial endommagé, fils de soie verts).
} 
religieux, les Teutoniques devaient obéissance au Pape. Pourtant Louis de Bavière prétendait que l'Ordre, comme ses terres, relevait de lui seul puisque ce sont des empereurs qui avaient «fondé, institué et doté l'ordre», dont les territoires étaient qualifiés de membra imperii - ce qu'ils n'avaient en réalité jamais été34! C'est, par conséquent, le roi de Pologne qui était un criminel, puisqu'il avait envahi des terres d'empire et y avait perpétré maints massacres, incendies d'églises, qui plus est en se faisant aider de païens (les Samogitiens en l'occurrence), alors qu'au contraire l'Ordre défendait ces territoires contre les tribus baltes, au prix de son sang. La protection impériale était assortie d'une menace : il était interdit à l'Ordre de se rendre au procès, sous peine d'être dépossédé de ses terres et de ses droits! Menace fictive, qui n'était là que pour permettre aux Teutoniques de faire bonne figure devant le Pape. La contreattaque impériale reposait en définitive sur trois éléments : l'Ordre était innocent des crimes dont on l'accusait, il ne relevait pas de la justice pontificale et ses terres étaient «comme des membres de notre empire » (où l'on retrouve le thème, fréquent à l'époque, de l'Empire comme corps politique 35 ).

L'affaire était l'occasion d'affirmer la toute puissance impériale y compris hors des frontières de l'empire et donc de limiter le champ où la Papauté pouvait exercer son autorité. A terme, ces éléments, fort utiles en la circonstance, pouvaient se retourner contre l'Ordre et menacer son indépendance; il est toutefois peu probable que Louis de Bavière en ait eu l'intention ou ait songé à annexer la Prusse. Mais il est néanmoins extraordinaire de constater que le document impérial prend le contre-pied de la bulle de Rimini (1226/1235) par laquelle Frédéric II instituait l'Ordre comme seul maître de la terre de Prusse, en

\footnotetext{
34 «En vérité puisque votre ordre a été fondé, institué et doté par les dits princes empereurs et rois des Romains pour la défense de l'Empire et de la foi chrétienne, et que les plaintes portées contre votre ordre par le dit Casimir paraissent nous toucher nous et l'empire principalement, et vous en tant que nos membres et membres de notre empire $(\ldots)$ ), $\operatorname{Pr} . U B$, III-1, n 183 . La Prusse teutonique n'a jamais appartenu à l'Empire ni au royaume de Germanie.

35 Jacques Krynen, L'empire du roi: idées et croyances politiques en France, XIIIe-XVe siècles, Paris, Gallimard, 1993, $556 \mathrm{p}$.
} 
se gardant bien de l'insérer dans l'empire... 36 Louis de Bavière ne se mêlera d'ailleurs plus guère par la suite du conflit entre les Teutoniques et la Pologne et, en particulier, sera absent du processus conduisant à la paix de Kalisch en 1343.

Dans ces conditions, il est logique de voir l'Ordre s'abstenir de répondre aux citations. Le jour même du procès, le 4 février, ses procureurs, Martin, chanoine d'Ermland et prêtre à Elbing, Jakob, prêtre à Biskupitz, et Bando, un clerc pomésanien expert en droit 37 , contestent la légitimité de Pierre Gervais et Galhard de Carcès et interjettent appel auprès du pape qui représente la juridiction supérieure 38 . La démarche est parfaitement reconnue en droit canon, et effectuée suivant les règles, sous la forme d'un document précis, long de trois pages. L'argument central porte sur la détention des terres de Culm, de Pomérélie et de Michelau, dont les procureurs nient que l'Ordre les ait envahies, rappelant au contraire qu'il les possède de longue date, en vertu de titres de propriété authentiques ${ }^{39}$. Cela permettait de réfuter les affirmations polonaises, et on s'explique ainsi pourquoi les juges pontificaux ont cherché à établir que les donations faites à l'Ordre n'étaient pas perpétuelles.

Bien évidemment l'appel devant être examiné par les juges eux-mêmes, les chances d'aboutir étaient nulles. Le rejet de Galhard de Carcès et Pierre Gervais, prononcé dès le 8 février, est très longuement justifié, tout en se

\footnotetext{
36 Sylvain Gouguenheim, L'Empereur, le grand maitre et la Prusse. La Bulle de Rimini en question (1226/1235), Bibliothèque de l'Ecole des Chartes 162 (2005), S. 381-420 (avec bibliographie récapitulative sur la question).

37 ... magister Bando Pomezaniensis diocesis licentiatus in legibus, Lites, t. I, p. 89.

38 Lites, t. I, p. 89-94; Pr.UB, III-1, nº 220 (original : GSPK, XXe Abt., Pg. Uk. Sch. 60, n 21b). Dans leur dernier appel les procureurs de l'Ordre, reprennent de nouveau le vocabulaire classique du droit en qualifiant la sentence de frivola, frustratoria et inanis et lui refusant jusqu'à l'appellation même de «sentence » : a dicta sententia, si sententia dici meretur, tamquam ab iniqua,Lites, t.I, p.134.

39 «Dans l'exposé des conclusions il y a manifestement une expression fausse lorsqu'il est dit que le maitre et les frères ont occupé par la violence les terres de Culm, de Poméranie et de Michelau, et qu'ils les tiennent sous leur occupation, car il est notoire pour tous que mes seigneurs, le maître et les frères du dit ordre sont entrés en possession de ces terres de bonne foi et légalement et qu'ils les ont légitimement possédées depuis longtemps, après les avoir reçues et obtenues. », (Lites, t. I, p. 91). En fonction des documents qui ont été conservés, force est de reconnaître qu'en effet le Culmerland fut donné à l'Ordre par Conrad de Masovie, tandis que la Pomérélie et la terre de Michelau furent toutes les deux achetées par les Teutoniques, la première en 1309, la seconde en 1317 auprès du duc Leszek de Leslau.
} 
fondant sur deux éléments essentiels qui prouvaient à leurs yeux que l'Ordre était un usurpateur: la fama publica ainsi que « l'évidence manifeste des faits », c'est-à-dire la notoriété, dont le poids en droit était plus lourd encore que celui de la fama 40 . En des termes juridiques habituels l'appel de l'Ordre était dénoncé comme «frivolis », « inanis » et les juges n'y voyaient qu'une vaine manœuvre dilatoire. Il est en effet probable que l'Ordre tentait de gagner du temps ou escomptait un vice de forme en sa faveur; il ne pouvait guère espérer intimider des juges assurés du soutien pontifical et de la protection de la monarchie polonaise. Les juges néanmoins, conformément aux exigences du droit canon, accordèrent un délai de six mois à l'Ordre pour produire ses preuves (cum omnibus actis et munimentis suis).

Mais, étrangement, comme le note H. Chlopocka, ce dernier n'a pas utilisé ses diplômes pour se défendre. Par la suite ses procureurs pratiquèrent la politique de la chaise vide, ce que l'on peut expliquer de différentes façons. Y voir du dédain ou du mépris semble superficiel. Les commissaires délégués par le grand maître jouèrent en fait de tout l'outillage juridique en leur possession et qu'ils paraissent bien maîtriser. D'une part, ils pouvaient s'abriter en prétendant obéir aux injonctions impériales. D'autre part, ils adoptèrent une attitude logique, puisqu'ils firent appel en récusant la légitimité de leurs juges. Il n'est enfin pas exclu que leur démarche ait visé à utiliser certains avantages de la contumace, même si, en l'occurrence, ils faisaient erreur. S'il arrivait en effet en cas de contumace, que le procès d'accusation ne puisse être tenu et que le juge ne puisse ni instruire la cause ni prononcer la sentence, cela était toutefois de plus en plus rare depuis le XIIIe siècle, où s'était forgée l'habitude de considérer que le contumax prouvait sa culpabilité par son absence. De plus, la litis

\footnotetext{
40 ... ymmo constat de contrario per famam publicam et facti evidenciam manifestam, Lites, t. I, p. 104 ; Pr.UB, III- $1, \mathrm{n}^{\circ} 222$ (extraits).
} 
contestatio, la présentation de l'accusation avait déjà eu lieu; la procédure pouvait donc en droit continuer 41 .

Quoi qu'il en soit, sachant que le procès était joué d'avance, l'Ordre choisit de tout miser sur ses possibilités de pression directe en Avignon, par l'intermédiaire de son procureur à la Curie. En déplaçant le lieu de la confrontation, en jouant de ses relations, il pouvait espérer contourner l'obstacle représenté par le tribunal de Varsovie et faire trancher en haut lieu l'affaire en sa faveur.

\section{Les chefs d'accusation et la procédure}

Les actes présentent les articles que le demandeur doit mettre par écrit et faire communiquer à l'accusé, lorsqu'il a l'intention de citer des témoins : ceuxci devront faire porter leurs dépositions sur les points évoqués dans ces articuli. Les trente chefs d'accusation ou sujets d'enquête introduits par le procureur du roi de Pologne tournent autour de l'illégalité de la présence de l'Ordre dans le Culmerland, la Cujavie et les terres de Dobrin et Michelau.

Les trois premiers portent sur le statut du Culmerland, les cinq suivants sont relatifs à la Pomérélie ( ${ }^{\circ} 4$ à 8 ), puis viennent trois articles concernant le duché de Cujavie ( ${ }^{\circ} 9-11$ ); les quatre points que l'on rencontre ensuite traitent de la situation de la terre de Dobrin $\left(\mathrm{n}^{\circ}\right.$ 12-15). Ces territoires sont déclarés appartenir au royaume de Pologne ou à son Eglise, la preuve en étant qu'ils ont autrefois payé le denier de Saint-Pierre ; l'Ordre les occupe donc illégalement. Tout cela est présenté comme notorium ou confirmé par la fama (de hoc est publica vox et fama). L'usurpation de la terre de Michelau est abordée dans les articles 16 à 18, avant que ne soient énumérés en 11 points les crimes imputés à l'Ordre ( $\mathrm{n}^{\circ}$ 19-29) : incendies de forteresses, de villages, d'églises, de couvent

\footnotetext{
41 Dans le texte de la sentence, Pierre Gervais et Galhard de Carcès rappellent que le procureur du roi de Pologne, Bertold de Ratibor, avait remis dès le 4 février son libellum seu peticionem suam (Lites, t. I, p. 137$138 ; \operatorname{Pr} . U B$ III-1, n 221 du 6 février 1339).
} 
franciscains, pillages, meurtres, viols, etc. Le dernier article établit à 115000 Marcs d'argent, au poids et à la monnaie de Pologne, le coût des dommages à rembourser.

Les juges procédèrent à une enquête sur la véracité des chefs d'accusation (par le recueil des témoignages), assortie d'interrogations sur le degré de notoriété des crimes imputés à l'Ordre, dans le cadre d'un procès inquisitoire « avec promoteur » (la cour de Pologne). Leur démarche suivait le détail de la procédure telle qu'Innocent III l'avait établie en $1215^{42}$. Chaque témoin fut interrogé sur l'ensemble des trente articles, dont l'ordre était scrupuleusement respecté. Les réponses sont indiquées dans le même ordre, et les enquêteurs notent systématiquement tout aveu d'ignorance. Lorsque le besoin s'en fait ressentir, les témoins sont invités à donner des précisions supplémentaires, à définir la fama ou à préciser par qui ils ont obtenu l'information qu'ils apportent. En fonction de ce qu'avance le témoin, les juges cherchent à en savoir plus. La déposition de Gunther, chancelier du duc de Masovie, donne un bon aperçu de ce procédé d'investigation méthodique qui procède par approximations successives afin d'approcher au plus près de la vérité :

« Interrogé sur le nom du duc qui avait concédé la terre de Culm aux Croisés, il répondit qu'il ne s'en souvenait pas. Interrogé sur le fait de savoir si la fama et l'opinion publique (publica vox) confirmaient que la terre de Culm, telle qu'elle était présentée et délimitée dans l'article susdit, était bien située au sein du royaume de Pologne, que les princes de Pologne l'avaient eu en leur possession, et qu'elle relevait bien de ce

\footnotetext{
42 Canon 8, Qualiter et quando, du concile de Latran IV. Paul Fournier, Les officialités au Moyen Age, Paris, 1880, réimpr. Aalen, 1984; Winfried Trüsen, «Der Inquisitionsprozess : seine historischen Grundlagen und frühen Formen », Zeitschrift der Savigny-Stiftung für Rechtsgeschichte, Kanonistische Abteilung, 74, 1988, p. 171-215. Ce régime procédural procède de la "clameur de la fama" qui prend en quelque sorte une personnalité juridique. Voir Claude Gauvard, De grace especial : crime, Etat et société en France à la fin du Moyen Age, Paris, 1991, 2 vol., p. 135-142, 734-743 ; ead. « la fama, une parole fondatrice », Médiévales, 24, 1993, p. 5-13; Julien Théry, Fama: l'opinion publique comme preuve judiciaire. Aperçu sur la révolution médiévale de l'inquisitoire, dans La preuve en justice de l'Antiquité à nos jours, Bruno Lemesle éd., Rennes, 2003 , p. 119147, ici p. 130.
} 
royaume, il dit qu'il en était ainsi, que c'était, comme il le dit, notoire, car c'est ce que l'on disait encore communément parmi les hommes du royaume et des territoires voisins. Interrogé sur le fait qu'il y avait des Polonais dans cette terre de Culm lorsqu'elle fut donnée aux Croisés, il répondit qu'il en était bien ainsi, à ce qu'il avait entendu dire et qu'il y en avait encore beaucoup $\gg 43$.

Bien que les témoins ne parlent que pour répondre aux questions, souvent le contenu de leur témoignage déborde du cadre prédéterminé et stéréotypé de l'interrogatoire. Les dépositions mêlent en effet rappels historiques généraux et événements de leur vie personnelle, éléments de la tradition orale, informations transmises au sein de leur famille ou de leur entourage, voire, plus rarement, des références à des documents écrits.

L'ensemble, à en juger par le style et le vocabulaire employés qui reflètent la variété des personnes interrogées, ne semble pas avoir été retouché ; il est en tout cas dépourvu d'aménagement juridique ou rhétorique. On dispose ainsi d'une bonne retranscription de la tradition orale, du moins telle qu'elle vivait dans la mémoire des témoins du procès.

\section{Des témoins à charge}

L'enregistrement des témoignages constitue le morceau de roi des actes. Les cent vingt six témoins - dont quarante et un clercs - sont tous membres du royaume de Pologne et certains figurent parmi ses plus illustres représentants. Tous sont cités à charge et s'expriment devant des juges qu'ils savent hostiles à des Teutoniques que le pape considère déjà comme coupables. Au sein des élites ducales figurent plusieurs membres de la famille des Piasts : Casimir « duc de Cujavie » (témoin $\mathrm{n}^{\circ} 43$; il est en fait simple duc de Gniewkowo/Argenau en

\footnotetext{
43 Lites, t. I, p. 143-144.
} 
Cujavie), Leszek duc de Leslau (témoin $n^{\circ} 105$ ) et Ladislas ancien duc de Dobrin et duc de Lęczyca (témoin ${ }^{\circ} 44$ ). Leszek de Leslau et Casimir de Cujavie étaient les fils de Siemomysl de Cujavie (1245/1250-1287) lui-même fils de Casimir duc de Cujavie (1233-1267), et petit-fils du duc Conrad (1210-1247). Siemomysl avait deux frères, le roi Ladislas Lokietek et Siemowit duc de Dobrin (1287-1306), père de Ladislas de Lęczyca (1337-1352) 44 . Les trois hommes étaient donc cousins du roi Casimir III, fils de Lokietek. On notera que Leszek était dans une situation inconfortable, car on lui reprochait d'avoir vendu la terre de Michelau aux Teutoniques en 1317, et cette vente était contestée lors du procès.

On rencontre par ailleurs de nombreux officiers palatins, des juges, des cives issus des cités victimes des combats. Les élites ecclésiastiques sont représentées par les principaux protagonistes du conflit avec l'Ordre allemand. $\mathrm{Au}$ premier rang se trouve Ianislas archevêque de Gniezno (témoin $\mathrm{n}^{\circ}$ 97). En 1320 il officia en tant que principal juge du procès intenté contre les Teutoniques. Son Eglise fut sévèrement touchée lors des combats de 13311332 ; en outre le sort de la Pomérélie l'intéressait au premier chef puisqu'une partie du duché relevait de sa province. Néanmoins, le prélat faisait partie de ceux qui souhaitaient un arrangement avec l'Ordre. A ses côtés se dressait une autre forte personnalité, Jean, évêque de Cracovie (témoin $\mathrm{n}^{\circ} 45$ ). Farouche adversaire de Casimir III pour des questions de prébende, il s'opposa constamment à sa politique et regroupait autour de lui tous les adversaires d'une paix avec l'Ordre, d'où sa communauté d'intérêt avec Galhard de Carcès. L'évêque Jean de Poznan (témoin n²), récemment installé sur son siège (1335) était également un adversaire de l'Ordre, ce que reflète bien son témoignage.

\footnotetext{
44 Siemowit de Dobrin mourut en 1306 ; Ladislas céda alors la terre de Dobrin à Ladislas Lokietek par crainte des Teutoniques. En 1329 celui-ci dut s'enfuir dans la terre de Lęczyca. En 1337 il renonça officiellement à la terre de Dobrin et Casimir III proclama son appartenance à la Pologne, bien qu'elle fût toujours sous le contrôle des Teutoniques. En échange de cette cession Ladislas obtint de Casimir le titre de duc de Lęczyca.
} 
La totalité des témoins sont hostiles à l'Ordre, et certains l'ont même vivement combattu. Les clercs notamment regroupent ses plus farouches adversaires, et leurs possibilités d'accès aux archives ainsi que leurs compétences juridiques font d'eux de redoutables témoins à charge. En outre, les rares prélats suspectés d'entretenir de bonnes relations avec l'Ordre ont été écartés du procès. Tel est le cas des évêques de Leslau et de Plock alors que la situation géographique de leurs diocèses en faisait des témoins essentiels : la Pomérélie appartenait en effet en grande partie au diocèse de Leslau, tandis que les terres de Dobrin et de Michelau relevaient de l'évêché de Plock. L'évêque de Leslau, Matthias Golanczewski, avait pourtant été un adversaire de l'Ordre et un partisan de Lokietek. Mais après les ravages subis par la Cujavie en 1329-1330, il conclut un accord avec les Teutoniques le 24 août 1330. On l'écarta par conséquent de la liste des témoins... Quant à Clément Pierzchala, évêque de Plock, il cumulait deux défauts rédhibitoires aux yeux de la partie polonaise : il était lié au roi Jean de Bohême et proche de l'Ordre 45.

\section{FAMA ET MEMOIRE COLLECTIVE}

\section{L'universelle « infamie » de l'Ordre}

La fama est au cœur du procès. La bulle de Benoît XII rappelait l'enquête des cardinaux sur l'infamia et le premier article du procureur polonais assimilait publica vox et fama en tant qu'éléments établissant sans discussion que le Culmerland avait de tout temps été au sein des frontières du royaume. D'emblée le procès s'installait dans le système classique où l'on use de la fama communis ou publica pour déterminer le degré de véracité des accusations, y compris s'il s'agit de droits de propriété. Ce premier chef d'accusation était en outre biaisé

45 Tel était aussi le cas de son prédécesseur, Florian, qui exerça sa charge lors des années de guerre et mourut en 1334. 
car le vrai problème était celui de la donation ou non de ces terres aux Teutoniques : ceux-ci n'avaient en effet jamais remis en cause leur appartenance antérieure à la Pologne mais prétendaient s'appuyer sur les donations du XIIIe siècle ou les achats du XIVe pour légitimer leur détention.

La fama s'apparente à la notoriété tout en s'en distinguant. La notoriété est ce qui ne peut être nié, qui a ipso facto valeur de preuve et permet donc de prononcer directement la sentence, tandis que la fama est ce que tout le monde dit ou sait 46 . Elle nécessite donc une vérification et, si elle est avérée, une procédure judiciaire; son usage s'est développé avec la procédure inquisitoire et sa définition est souvent, sinon toujours, exigée des témoins. Les procureurs de l'Ordre, on l'a vu, font usage de ce qui est notorium dans leur appel et les témoins parlent tantôt de la fama tantôt du notorium pour accréditer leur témoignage : tout le monde use des mêmes armes.

Les juges veulent presque systématiquement qu'on leur définisse la fama et qu'on leur indique auprès de qui elle est répandue 47 . Il s'agit d'établir quel phénomène cette renommée représente et d'identifier les cercles au sein desquels elle circule. De la valeur sociale ou de la compétence des hommes qui colportent la rumeur dépendent en partie le crédit que l'on accorde à celle-ci.

J. Théry souligne que « demander sans cesse au témoin de définir la fama comme mode de connaissance, c'était pédagogiquement lui en faire reconnaître à chaque fois l'imperfection - au regard de la vérité, objet du travail de l'institution qui présidait à l'enquête » 48 . Il semble qu'au-delà d'un instrument de domination intellectuelle, on puisse aussi y déceler un souci d'éviter tout vice

\footnotetext{
46 Les juristes vont faire de la notoriété « la reine des preuves » Julien Théry, Fama, op. cit., p. 142. Claude Gauvard signale que «la théorie du notoire serait une création originale du droit canonique et sans aucun précédent romain » (De grace especial..., p 136 note 103 avec renvois à Pierre Legendre, Le droit romain, modèle et langage..., p. 912, note 17 et Jean-Philippe Lévy, Le problème de la preuve dans les droits savant du Moyen Age, La preuve, Recueils de la société J. Bodin, Bruxelles, 1963-1965, t. 17, p. 137-167, ici p. 137).

47 Dans les plus longues dépositions, telle celle de Jean de Poznan, la demande de définition de la fama ou du « notoire » n'est pas réitérée chaque fois que l'expression est utilisée par le témoin ; mais elle l'est néanmoins très souvent.

48 Julien Théry, Fama..., op. cit., p. 145.
} 
de forme dans le procès, l'accusation pouvant réfuter un témoignage appuyé sur la fama ou le «notoire » qui ne rappellerait pas la définition de ces termes. Au surplus, un tel témoignage, isolé de l'ensemble des actes, n'aurait pas valeur de preuve si les définitions en question y manquaient.

Les définitions de la fama fournies par les témoins sont en général assez proches. Elle est «ce que 1 'on dit communément ${ }^{49}$, «ce qui est dit en public » 50 , « ce qui est dit et murmuré depuis des temps anciens et que 1'on dit encore par toutes les cités et les terres du royaume de Pologne $» 51$, « ce qui est dit et affirmé parmi les hommes probes, anciens, prudents et de valeur » - où la qualité du témoin légitime celle du témoignage 52 . Le miles Andréas, châtelain de Rosperz, donne une définition intéressante qui prend en compte le processus de transmission de la fama: «ce que nos parents ont vu et qu'ils ont dit et transmis à nous et à leurs descendants » 53 .

Ce qui est notoire est sans surprise défini comme « ce que tous savent et ce qui est connu de tous » 54 , « ce qui ne peut être nié et que tous savent » 55 ; le miles Martin, chambrier de Leczyca déclare notoire ce qui « est visible et que tous savent $» 56$, définition reprise par beaucoup en des termes fort proches, qui montre que l'on ne distingue pas toujours bien entre la fama et le notorium. Le notoire c'est «ce que tout le monde sait» dit encore le miles Boguslaus,

\footnotetext{
49 Illud quod communiter dicitur (témoin ${ }^{\circ}$ 2, Jean évêque de Poznan, Lites, t. I, p. 149); le témoin $\mathrm{n}^{\circ} 3$, Presdrew chanoine de Poznan, la définit ainsi : est quod omnes homines locuntur (Lites, t. I, p. 157).

50 Quod dicitur et auditur publice, (Pierre prévôt de Leczyca, témoin $n^{\circ} 29$, Lites, t. I, p. 247). Définition d'ailleurs redondante car elle répond à la question quid est publica vox et fama?

51 Quod ab antiquo dicebatur et murmurabatur et adhuc dicitur per omnes civitates et terras regni Polonie (Paul, officier palatin de Lęczyca, témoin $\mathrm{n}^{\circ}$ 7, Lites, t. I, p. 177).

52 Illud, quod inter probos homines et antiquos discretos et valentes dicitur et asseritur assertive (Mathias, archidiacre de Plock, témoin $n^{\circ} 4$, Lites, t. I, p. 163).

53 Quod nostri parentes viderunt et nobis et suis posteris dixerunt et retulerunt (témoin $\mathrm{n}^{\circ} 27$, Lites, t. I, p. 241).

54 Illud,quod omnes sciunt et omnibus est notum (Presdrew chanoine de Poznan, Lites, t. I, p. 159 ; auparavant il a également défini ce qui est notoire comme : quod omnes sciunt et apparet per evidenciam facti (ibid.) ou encore quod omnibus est notum et non indiget probatione (ibid.).

55 Illud quod non potest negari (André chancelier de l'Eglise de Poznan, témoin n ${ }^{\circ}$, Lites, t. I, p. 173).

56 quod oculis videtur et omnes sciunt, (Martin, chambrier de Lęczyca, Lites, t. I, p. 249, témoin n 31).
} 
pourtant capable de le définir à un autre moment comme «ce qui est public, manifeste et ne peut être nié ${ }^{57}$.

Lorsque les juges veulent savoir auprès de qui les faits énoncés sont répandus et par qui ils sont confirmés, les témoins tendent alors à faire valoir leur universalité, ou l'éminence sociale de ceux qui les rapportent. Parfois c'est ce que disent la majorité des gens 58 . Yves, chanoine de Cracovie prend le soin de préciser que ce qu'il sait est attesté « non par cent mais par mille et par tous » et que, par conséquent, ce qu'il dit est vrai 59 . Jean évêque de Poznan affirme que ce qu'il avance est partagé par les chevaliers et les personnes importantes du royaume : c'est ce que tout le monde dit lorsque le sujet est abordé60. L'opinion $\mathrm{du}$ « vulgaire » est aussi prise en compte : Etienne, prévôt de Plock, déclare que la fama est « ce qui est communément dit par des personnes importantes et par les autres gens du peuple »61. L'étendue géographique de la fama peut enfin sans difficulté remplacer l'estimation numérique. Presdrew, chanoine de Poznan, déclare que la fama dont il se fait l'écho est répandue « dans le royaume de Pologne, en Masovie et par toutes les terres du dit royaume »62 et l'archevêque de Gniezno n'hésite pas à déclarer que ce qu'il avance est connu des hommes du royaume de Pologne mais aussi des régions voisines... 63. Enfin les témoins distinguent à la demande des enquêteurs entre ce qu'ils savent, ce qu'ils ont vu de leurs propres yeux, ce qu'on leur a dit, éventuellement ce qu'ils ont lu: tout cela est classique de la procédure inquisitoire.

\footnotetext{
57 ... quod scitur ab omnibus,(Boguslas Lazanka, miles de Lęczyca, témoin $\mathrm{n}^{\circ}$ 32, Lites, t. I, p. 257); illud, quod publice et manifeste fit et non potest negari (ibid., p. 258).

58 Quod ab omnibus vel parte maiori predicatur et dicitur (Jean, abbé de Saint-Adalbert de Plock, témoin $\mathrm{n}^{\circ} 11$, Lites, t. I, p. 194).

59 Non a centum, sed a mille et ab omnibus dicitur, quod ita verum est ut dixit (Yves, prévôt de l'Eglise de Gniezno, témoin $n^{\circ} 17$, Lites, t. I, p. 210)

60 Apud milites et graves personas regni Polonie... quandocumque tractatur de ista materia, ita dicitur ab omnibus ut dixit, (Lites, t. I, p. 149); on reconnaît dans l'expression graves personas la formule boni et graves homines - les « gens de bien »- habituelle dans la procédure d'enquête liée à la fama.

61 Quod communiter dicitur a gravibus personis et ab aliis de vulgo, (Lites, t. I, p. 190).

62 In regno Polonie et in Mazovia et per omnes terras dicti regni Polonie (Lites, t. I, p. 160).

63 Quia adhuc communiter dicitur inter homines regni Polonie et partibus circumvicinis...(Lites, t. I, p. 144).
} 
La fama apparaît bien comme un «matériau pour l'enquête » 64 . Les juges exercent en l'occurrence un travail de vérification de la valeur des témoignages, de «véridiction », qui ne porte pas sur la réputation et l'honneur des Teutoniques, mais sur la véracité d'un certain nombre de faits : statut juridique des terres contestées, réalité des crimes commis lors des épisodes guerriers, etc. $\mathrm{Au}$ cœur de leur démarche gît l'idée qu'un élément avancé par le plus grand nombre est exact: «la renommée se structure dans la collectivité pour s'exprimer dans l'anonymat » 65 ; la foule valide le témoignage d'un individu. La fama, la vox publica, est bien porteuse de vérité et s'auto-légitime par le fait même de son existence.

\section{Mémoire et histoire : la « fausse donation » du Culmerland}

Le Culmerland fut la première terre offerte aux Teutoniques par le duc Conrad de Masovie lorsqu'il fit appel à l'Ordre vers 1225-1226 pour l'aider à protéger sa frontière septentrionale des attaques païennes. Après quelques années de négociations, scandées par la rédaction de plusieurs accords préparatoires, les Teutoniques obtinrent l'intégralité du territoire, assorti de l'ensemble des droits seigneuriaux (traité de Kruschwitz juin 1230)66. La bulle impériale de Rimini (1226/1235) et la décision pontificale de Riéti (août 1234) conférèrent à l'Ordre la propriété de cette région, des droits équivalents à ceux des Princes d'Empire, et une réelle indépendance. Au long du XIIIe siècle, que les Teutoniques consacrèrent à la guerre contre les tribus prussiennes, aucun prince polonais ne remit en cause leur présence dans le Culmerland, même si des litiges apparurent concernant la possession de certains villages ou territoires

64 Julien Théry, Fama, op. cit., p. 140.

65 Cl. Gauvard, De grace especial..., p. 140.

66 Pour une présentation détaillée de ces problèmes : Sylvain Gouguenheim, Les Chevaliers teutoniques, Paris, Tallandier, 2007; id., Gregor IX., Wilhelm von Modena und die Herrschaftsbildung des Deutschen Ordens (vom Kruschwitzer Vertrag zur Bulle von Rieti 1230-1234), Ordines militares, Colloquia Torunensia, XIV, Torun, 2007, p. 87-103. 
voisins, telle la terre de Dobrin. En fait, Polonais et Teutoniques étaient alliés contre leur ennemi commun. Au contraire, à partir des années 1326-1330, le Culmerland fut revendiqué par la monarchie polonaise et son sort constitua l'objet des trois premiers articles de 1339. L'enquête portait sur les deux points suivants: l'appartenance du Culmerland à la Pologne (article $\mathrm{n}^{\circ} 1$ ), et le paiement par ses habitants, comme par l'ensemble du royaume de Pologne, du denier de Saint-Pierre, qui permettait d'affirmer l'illégalité de la détention par les Teutoniques de cette «partie du royaume » $\left(\operatorname{article~} n^{\circ} 3\right)^{67}$. Le premier point n'est abordé que par trente deux témoins sur cent vingt six, et celui du paiement du denier de Saint-Pierre par les habitants du Culmerland par vingt-huit (en général ceux qui déposent au sujet du premier article); les autres ne savent rien du sujet, ce qui peut surprendre et laisse en tout cas penser que les dépositions n'ont pas été manipulées.

Ceux qui s'expriment sont unanimes: la terre de Culm, qui appartenait à la Pologne, fut octroyée à l'Ordre en échange de son intervention militaire contre les Prutènes, pour une durée limitée. Beaucoup reconnaissent toutefois ne pas avoir d'informations précises. La prudence anime plusieurs témoins, qui déclarent ne pas être certains de la situation car les faits relatés se sont produits il y a longtemps 68 . Mathias, châtelain de Gnewow en Cujavie, tout en signalant que les Teutoniques auraient dû restituer cette terre, refuse d'en dire plus et s'abrite en déclarant qu'il s'agit d'une affaire ancienne (antiquum negotium est $)^{69}$; Etienne, prévôt de Płock, dit ne pas savoir pour combien d'années le Culmerland avait été donné par Conrad70. Le miles Albert de Luscowo dit

${ }^{67}$ L'article $\mathrm{n}^{\circ} 2$ servait de lien entre les deux éléments, en rappelant que la Pologne payait le denier de SaintPierre. Le syllogisme qui structurait la démarche était le suivant: la Pologne paye le denier de Saint-Pierre, le Culmerland payait le denier de Saint-Pierre en tant que partie du royaume polonais, sa domination par les Teutoniques est donc une usurpation.

68 Matthias, archidiacre de Płock (Lites, t. I, p. 162) explique que c'est une affaire ancienne (antiquum negotium) et qu'il ne sait pas par quel biais le Culmerland est passé aux mains des Teutoniques (...et nescit per quem modum devenit ad magistrum et fratres Cruciferos).

69 Lites, t. I, p. 237.

70 Lites, t. I, p. 191. 
même tout ignorer des conditions de la donation ${ }^{71}$. Il est intéressant de constater que même des membres des élites disent ne rien savoir des conditions de la présence des Teutoniques dans le Culmerland et refusent de se prononcer sur sa légitimité, en particulier Ladislas duc de Lęczyca! Et de son côté l'évêque de Poznan avoue ne pas savoir si la donation fut temporaire ou perpétuelle (utrum in perpetuum, vel ad tempus, dixit se nescire) mais il précise qu'il a souvent entendu dire que les Teutoniques auraient dû rendre le Culmerland à Conrad ou à ses héritiers 72 .

Dix-neuf témoins avancent que le Culmerland avait été donné par les ducs de Pologne aux Teutoniques. L'information vient de leurs parents, ou autres membres de leur famille plus âgés (a senioribus). Dix-huit d'entre eux affirment que la donation par la Pologne aux Teutoniques n'était que temporaire - voire limitée à vingt ans - et que les Teutoniques auraient dû la restituer au bout de ce délai ou une fois les païens vaincus. On trouve cet argument dès la déposition du premier témoin, Gunther, chancelier de Troyden duc de Masovie:

« ... le père du seigneur Wladislas jadis roi de Pologne possédait et tenait la dite terre de Culm en paix et en sûreté comme un bien patrimonial, et il transmit et concéda cette dite terre pour vingt ans au maître et aux frères de l'hôpital de sainte Marie des Allemands qui étaient alors en Prusse pour combattre les infidèles et les ennemis de la foi chrétienne, les Prutènes qui étaient alors les voisins de la dite terre de Culm ou qui résidaient à ses confins, et une fois écoulées les vingt années, ils devaient restituer la dite terre de Culm au dit seigneur duc de cette

\footnotetext{
71 Lites, t. I, p. 217 ; Martin chambrier de Lęczyca précise qu'il doit ce qu'il sait à ses parents, n'étant lui-même pas né à l'époque car l'affaire est ancienne (non erat natus, ita antiquum negotium est), Lites, t. I, p. 249.

72 Lites, t.I, p. 149. Il tient cette information de ses parents (quia audivit a senioribus suis) et soutient que c'est ce que disent les gens chaque fois que le sujet est abordé (...quod illus, quod communiter dicitur, et quandocumque tractatur de ista materia, ita dicitur ab omnibus ut dixit).
} 
terre, qui la leur avait concédée, ou à ses héritiers. Ils refusèrent de le faire, et le refusent encore ainsi que les faits le montrent... » 73 .

Certains témoins affirment enfin qu'existent des diplômes attestant ce caractère temporaire, et cinq d'entre eux disent même avoir vu ces documents. Ce sont ces témoignages que nous allons maintenant examiner.

\section{Les preuves documentaires d'une usurpation?}

Six témoins sont particulièrement intéressants: l'inquisiteur Nicolas, prieur du couvent dominicain de Sieradz (heretice pravitatis in Magna Polonia, prior conventus Predicatorum de Siradia), Predslaus, archidiacre de l'église de Gniezno, Jean évêque de Cracovie, Ianislas archevêque de Gniezno, Leszek duc de Leslau et Pierre écolâtre de Sandomir 74 .

Le frère prêcheur Nicolas fut lecteur du couvent de Culm ainsi que prieur à Elbing. En 1331, en pleine guerre, il se jeta aux pieds du commandeur teutonique d'Elbing, le suppliant d'épargner la cité de Sieradz. En vain, la ville fut dévastée. Sa déposition apporte deux éléments originaux. D'une part, il affirme qu'un légat pontifical jadis en mission en Prusse croyait que le Culmerland appartenait à cette province ecclésiastique. Quand on lui signala que tel n'était pas le cas, il enleva ses insignes de légat et ne les reprit qu'une fois passée la rivière Ossa, qui marquait la frontière avec la Prusse. Le fait aurait été rapporté à Nicolas par les témoignages de plusieurs de ses frères prêcheurs. On n'en a pas conservé de trace par ailleurs. L'histoire témoigne d'une certaine confusion. L'Ordre comme la Papauté distinguaient en effet soigneusement dans leurs écrits la Prusse et le Culmerland, principalement en raison du fait que le Culmerland avait été donné par le duc de Masovie, en tant qu'ancienne

\footnotetext{
73 Lites, t. I, p. 143.

74 Témoins $n^{\circ} 33,42,45,97,105$ et 106.
} 
possession, tandis que la Prusse, qui n'avait jamais fait partie de la Pologne, avait été entièrement à conquérir. Dans la bulle de Riéti d'août 1234, Grégoire IX prenait sous le droit et la propriété de Saint-Pierre l'ensemble des terres païennes de Prusse pour les redonner aussitôt à l'Ordre ; il n'y incluait pas le Culmerland pour la raison évoquée à l'instant 75 . Lors de la création des diocèses en 1243, la Papauté distingua le Culmerland, qui constitua un diocèse à lui seul, de la Prusse, divisée en trois évêchés. L’Ordre de son côté partagea les terres de Prusses en commanderies, tandis que le Culmerland constituait un bailliage (jusqu'en 1336), administré par un «Landkomtur », subordonné au maître de Prusse, et divisé en une dizaine de commanderies 76 . L'expression cives Culmensis terrae, présente dans certains diplômes au XIIIe siècle, montre que le Culmerland était doté d'une identité propre, au sein de la Prusse77. Néanmoins, en tant que diocèse, il relevait de la province ecclésiastique de Prusse, non de celle de Gniezno.

Pour toutes ces raisons, l'histoire rapportée par Nicolas semble témoigner d'une confusion, voire d'une manipulation du légat par les ecclésiastiques locaux. Il est possible d'en trouver l'origine dans le fait que le Culmerland dépendait au début du XIIIe siècle de l'évêque de Plock, donc de la métropole de Gniezno; fait qu'évoque d'ailleurs l'archidiacre de Gniezno, Predslaus78. Mais lorsqu'un évêque missionnaire, le moine Christian, fut nommé «évêque des Prutènes » par le pape en 1215, le Culmerland fut alors placé sous l'autorité directe de Rome. Dès 1218 Honorius III autorisa Christian à créer des diocèses

\footnotetext{
$75 \operatorname{Pr} . U B, \mathrm{I}-1, \mathrm{n}^{\circ} 108$.

76 Klaus Militzer, Von Akkon zur Marienburg. Verfassung, Verwaltung und Sozialstruktur des Deutschen Ordens 1190-1309, in Quellen und Studien zur Geschichte des Deutschen Ordens, Bd. 56, Marburg, 1999, 547 p. $77 \operatorname{Pr} . U B, \mathrm{I}-1, \mathrm{n}^{\circ} 206$ de juillet 1248.

78 Lites, t. I, p. 277 : Dixit eciam, quod dicta terra Culmensis fuit de diocesi Plocensi, que est infra regnum Polonie, sed postea procurantibus dictis Cruciferis est factus et creatus episcopatus de novo a modernis temporibus in dicta terra Culmensi et vocatur episcopatus Culmensis ut dixit.
} 
en Prusse, montrant par là que l'on envisageait la formation d'une nouvelle province ecclésiastique (qui ne vit le jour en fait qu'en 1246) 79 .

Le second volet du témoignage de l'inquisiteur Nicolas apporte un élément inédit :

« Il dit aussi que le grand-maître des Croisés de Prusse, Charles [Charles de Trèves (1311-1324)], le fit un jour venir dans leur forteresse de la Marienbourg, alors qu'il était prieur à Elbing, et lorsqu'il fut arrivé auprès de lui dans le château, le grand-maître lui montra de nombreux privilèges et lettres de l'Ordre, parmi lesquels se trouvait un privilège sur la concession de la terre de Culm aux Croisés, indiquant comment elle leur avait été et leur était concédée par les princes polonais, à qui la dite terre de Culm avait appartenu et appartenait; le témoin qui parle a vu et lu ce privilège au mot près, à ce qu'il dit. Interrogé sur ce que contenait le dit privilège, il dit que la dite terre de Culm avait été concédée aux Croisés par cet accord et à la condition qu'une fois vaincus et soumis les Prutènes et les infidèles qui étaient sur l'autre rive de l'Ossa, ils restituent cette dite terre à ces princes qui la leur avaient donnée et concédée, ou à leur héritiers. Tout ce que les dits Croisés pourraient acquérir au-delà de l'Ossa, devait entièrement être à eux, d'après ce que contenait le dit privilège fait pour cette concession, qu'il a, à ce qu'il dit, vu et lu. » 80

Malheureusement il est incapable de donner le nom d'un seul des princes polonais auteurs de cette donation... Par ailleurs on n'a conservé aucun diplôme indiquant que la donation du Culmerland n'était que temporaire alors que celle des terres au nord de l'Ossa aurait été perpétuelle81. Quoi qu'il en soit, on

\footnotetext{
$79 \operatorname{Pr} . U B, \mathrm{I}-1, \mathrm{n}^{\circ} 19$.

${ }^{80}$ Lites, t. I, p. 260.

81 Nicolas est le seul témoin à parler de cet acte, mais la donation perpétuelle des terres au-delà de l'Ossa est
} 
comprend le sens de la déposition : la possession du Culmerland seule intéresse les Polonais, peu leur importe que l'Ordre contrôle la Prusse. Il s'agit, conformément à la politique générale voulue par Casimir III, de reconstituer l'unité et l'intégralité du royaume de Pologne, au sein de ses anciennes frontières, non de s'étendre en annexant la Prusse. On devine également les ambitions de l'Eglise de Gniezno cherchant à prendre en mains un diocèse dont le territoire avait jadis dépendu d'elle, lorsqu'il n'était encore qu'une marche frontalière de la Masovie.

Predslaus archidiacre de Gniezno, dont le père fut officier palatin du duc de Cujavie et qui appartient aux cercles politiques intéressés par le procès, déclare que la terre de Culm relève du royaume de Pologne et rapporte avoir lu dans une «Chronique des Polonais » que Conrad de Masovie donna la terre aux Teutoniques 82 . Il ne fournit aucune indication quant à la durée de cette donation. C'est l'unique fois qu'un témoin s'appuie sur des sources historiques ; il se pourrait que l'ouvrage en question fût la «Chronique de Pologne » de l'évêque Boguphal de Poznan (1242-1252) 83. Or cette chronique mentionne que Conrad de Masovie céda dans un premier temps le Culmerland pour une durée de vingt ans seulement, ce qu'aucun diplôme n'atteste, avant d'étendre la concession à perpétuité, sur les instances de son allié le duc Henri de Silésie 84 .

également rapportée par l'officier palatin Albert de Brest, Martin chambrier de Lęczyca et Pierre écolâtre de Sandomir (respectivement les témoins $n^{\circ} 81,31$ et 106).

82 Lites, t. I, p. 277.

83 Issu d'une famille noble, Boguphal fut maître (1211) puis écolâtre (1218) au sein du chapitre cathédral de Poznan, avant de devenir chanoine (1231-1242). Sa chronique fut rédigée entre 1245 et 1253 . Max Perlbach, Preussich-polnische Studien, Bd. II, Halle, 1886, p. 41 estimait qu'elle était en fait une compilation du XIVe siècle. Les travaux plus récents de Brygida Kürbis montrent que l'œuvre est composite, mais qu'une partie fut sans doute rédigée au milieu du XIIIe siècle par Boguphal à partir des Annales de Grande Pologne : Brygida Kürbis, Dziejopisarstwo wielkopolskie XIII I XIV wieku ["L'historiographie de Grande Pologne aux XIIIe et XIVe siècles »], Polska Akademia Nauk, Instytut Historii, Varsovie, 1959, p. 10-21 et 162-169).

84 «En effet le dit duc de Masovie, Conrad, qui devait supporter les nombreuses attaques des Prutènes et des Polexiens dans la terre de Culm concéda pour vingt ans, sur le conseil de l'évêque Gunther, la terre de Culm aux croisés à la croix noire, les membres de l'hôpital de sainte Marie de Jérusalem de la maison des Allemands, afin qu'ils résistent aux Prutènes et aux Polexiens (...). Après le célèbre triomphe de leur victoire, le duc souvent cité, Henri, demanda à son oncle Conrad d'accepter d'accorder aux croisés la dite terre à titre perpétuel. A la suite de cette prière, Conrad accorda par don gracieux à ces hospitaliers la terre en question entre les fleuves Ossa, Vistule et Drewenz. », (Boguphali II episcopi Posnaniensis chronicon Poloniae, chap. 66, p. 559). 
C'est le premier témoignage narratif d'une donation temporaire, limitée à la durée nécessaire à la christianisation, voire cantonnée à une durée prédéterminée 85 . Le scénario proposé n'a rien d'impossible; il n'est malheureusement pas étayé par d'autres sources. Aucun des traités conclus entre 1228 et 1230 ne le confirme, puisque tous mentionnent que la donation du Culmerland a lieu à titre perpétuel 86 . Toutefois la présence des Teutoniques a peut-être au départ été envisagée comme temporaire comme le suggère cette phrase de Grégoire IX, dans la bulle du 12 septembre 1230 lorsqu'il déclare que les Teutoniques demeureront en Prusse «tant que la terre sera païenne», restriction qui disparaît dans la bulle de Riéti 87 . La présence de l'Ordre suscita néanmoins des oppositions dès le début. On sait que des vassaux de Conrad de Masovie se refusaient à laisser leurs biens du Culmerland entre ses mains. Le litige fut tranché par un accord conclu en 1235, dans lequel le duc confirmait à l'Ordre la perpétuité de ses possessions. Mal interprétée, cette décision pouvait laisser croire que la présence des Teutoniques avait jusque là été limitée dans le temps et que la donation n'était devenue perpétuelle qu'à la suite de pressions exercées de leur part 88 . Nous avons donc quelques maigres indices qui étayeraient les propos de Predslaus.

L'évêque de Cracovie, Jean, affirme de son côté que, quinze ans auparavant, donc en 1324, lorsqu'il était chancelier du roi Ladislas Lokietek en Cujavie, l'Ordre avait envoyé le commandeur de Graudenz, Sieghard von Schwarzburg, conclure la paix au sujet de la Pomérélie et du Culmerland :

\footnotetext{
85 Les chapitres précédents ( ${ }^{\circ} 64$ et 65 ) traitent d'événements survenus en 1231 et 1232; le chapitre suivant ( ${ }^{\circ}$ 67) se situe en 1238. Cela crée un intervalle chronologique qui est bien tardif si on l'applique à l'entrée en scène des Teutoniques (1228-1230).

86 Après un siècle de débats, l'authenticité de ces diplômes n'est plus mise en question; il s'agit des accords conclus à Biecz en avril $1228\left(\operatorname{Pr} . U B, \mathrm{I}-1, \mathrm{n}^{\circ}\right.$ 64), d'un traité préliminaire de $1230\left(\operatorname{Pr} . U B, \mathrm{I}-1, \mathrm{n}^{\circ} 75\right)$ et du traité de Kruschwitz de juin 1230 ( $\left.P r . U B, \mathrm{I}-1, \mathrm{n}^{\circ} 78\right)$.

87 dum tamen talis sit paganorum terra, in qua nondum cultus christiane religionis fuerit introductus, Pr. UB, I$1, \mathrm{n}^{\circ} 80$.

$88 \operatorname{Pr} . U B, \mathrm{I}-1, \mathrm{n}^{\circ} 119$.
} 
« ...le seigneur Ladislas réclamait ces terres et voulait les reprendre aux Croisés, parce qu'elles étaient siennes et relevaient de lui en raison de sa royauté; il disait entre autres que son aïeul, dont le seigneur évêque qui parle a oublié le nom, avait donné et concédé à titre précaire la dite terre de Culm aux dits frères Croisés, afin d'expulser les Prutènes infidèles qui vivaient dans les environs de cette terre, ayant passé un accord avec comme condition qu'une fois soumis les dits Prutènes, ils seraient tenus de restituer la dite terre de Culm, ses forteresses, ses villages, ses domaines, comme ils les avaient reçus, à l'aïeul du seigneur roi Ladislas ou à ses successeurs, pacifiquement et sans conflit. Et, au sujet de cet accord et de cette condition, le roi montra au dit frère Sieghard les lettres de celui qui était alors maître du dit ordre des Croisés, avec lesquels cet accord et cette condition avaient été conclus, et leur contenu écrit était ce qu'il avait dit. Interrogé sur le point de savoir s'il avait lu la lettre en question, il dit que non, car il était occupé par d'autres affaires du dit seigneur roi, mais qu'il l'avait bien vue. » 89

Jean occupa les fonctions de chancelier entre 1313 et 1324 et Sieghard a été commandeur de Graudenz entre 1313 et 1329, leur rencontre est donc possible voire plausible, au plus tard en 1324, soit à la fin du règne de Charles de Trèves. Nous n'avons pas conservé de document semblable à celui ici évoqué. Le «maître » en question ne pourrait guère être qu'Hermann de Salza (ou son émissaire Hermann Balk, premier maître de Prusse) puisque, selon le témoin, Ladislas Lokietek parle de la donation de son aïeul, c'est-à-dire Conrad de Masovie.

Le duc de Leslau, Leszek, rapporte un événement analogue. Il rappelle que Conrad de Masovie a concédé temporairement (ad tempus) le Culmerland

${ }^{89}$ Lites, t. I, p. 279. 
aux Teutoniques, afin qu'ils expulsent les Prutènes et les Lituaniens qui avaient franchi l'Ossa et à condition qu'ils la restituent ensuite:

«Et ce même témoin dit qu'il a vu et lu le privilège fait sur cette concession de la terre de Culm, qui était scellé du sceau du grand-maitre qui se nommait Papo. Il dit qu'il a souvent vu et tenu en mains ce privilège. Il dit aussi que son oncle paternel, Boleslas de Masovie, lui montra ce privilège pour qu'il se souvienne qu'ils avaient des droits sur cette terre de Culm, jusqu'au fleuve Ossa, et s'ils ne pouvaient la récupérer, qu'ils se souviennent au moins de la récupérer après sa mort, s'ils pouvaient. » 90

Il faut voir en «Papo » le grand maître Poppo d'Osterna (1252-1256). Boleslas (Boleslas II duc de Plock et de Mazovie, petit-fils de Conrad de Masovie) mourut le 20 avril 1313 : les événements relatés ont donc au moins vingt-six ans et la manière dont Leszek rapporte les propos de son oncle paternel fait songer à l'expression des dernières volontés d'un mourant... Mais il n'y a pas d'acte scellé de Poppo d'Osterna traitant de la donation du Culmerland aux Teutoniques. Si l'on accepte l'authenticité du témoignage de Leszek, il est possible d'admettre qu'il ait eu entre les mains l'accord du 28 décembre 1254, par lequel Casimir de Cujavie et Poppo d'Osterna s'entendaient sur la terre de Löbau, la Galindie et la Polexie; le duc renonçait à ces deux dernières mais obtenait la moitié de la région de Löbau (Casimir s'engageait par ailleurs à respecter les décisions de son père Conrad, autrement dit la cession du Culmerland à l'Ordre) ${ }^{91}$. Il se trouve que cet acte a été conservé dans ses deux versions, celle du grand maître et celle du duc, toutes deux portant les sceaux de

\footnotetext{
90 Lites, t. I, p. 375.

$91 \operatorname{Pr} . U B, \mathrm{I}-1, \mathrm{n}^{\circ} 303$.
} 
leurs émetteurs 92 . Cela fournit un indice en faveur de l'authenticité du témoignage.

Le récit de l'archevêque de Gniezno apporte un autre éclairage sur la question. D'une part il affirme avoir entendu dire par son prédécesseur, et par d'autres milites et nobles du royaume, que le Culmerland appartenait à la Pologne, et que Conrad l'avait cédé à condition que les Teutoniques le restituent une fois les païens vaincus. Il ajoute un deuxième point, qui recoupe la déposition de Leszek de Leslau :

« Il dit aussi qu'il a vu, chez le seigneur Wanco duc de Płock et petit-fils du duc Conrad, une lettre de protestation du dit duc Conrad, dans laquelle il protestait ainsi: ce même duc Conrad avait concédé la dite terre aux dits Croisés pour qu'ils attaquent les Prutènes infidèles, et une fois ceux-ci vaincus, ils devaient restituer la dite terre à lui ou à ses héritiers, et le contenu de la lettre était ce qu'il dit. »93

Ianislas de Gniezno appelle cette lettre, que l'on n'a pas conservée, protestationes protestatorias, mais il n'en dit pas plus : à quelle protestation, à quelle affaire cela peut-il faire allusion ? La seule hypothèse plausible, à ma connaissance, est le litige de 1235 évoqué plus haut et réglé par l'intermédiaire du légat Guillaume de Modène : l'Ordre cédait la terre de Dobrin mais se voyait confirmer à perpétuité les territoires de Nessau, Sedlce, Orlow et le village de Rogow en Cujavie, tandis que Conrad s'engageait à expulser ses propres vassaux chasés dans le Culmerland afin de laisser le champ libre aux Teutoniques 94 . Wanco (Wenceslas) duc de Plock puis duc de Masovie mourut

\footnotetext{
92 GSPK, Hauptabt. XX, Pg. Uk., Sch. 58, 6 pour l'acte portant le sceau de Casimir et Sch. 58, 32 pour celui scellé par Poppon d'Osterna.

93 Lites, t. I, p. 366-367.

94 Pr. UB, I-1, nº 119.
} 
en $1336^{95}$. Il était le fils du Boleslas dont on a parlé à l'instant, et donc l'arrièrepetit-fils en ligne directe de Conrad. Le témoignage de Ianislas reprend ainsi ceux de Jean de Cracovie et Leszek de Leslau.

La déposition de Pierre, écolâtre de Sandomir, tout en allant dans le même sens est moins précise. Il affirme avoir vu un jour apporter au roi Ladislas Łokietek un coffret renfermant des privilèges:

« Il dit que lorsque mourut l'un des procureurs du dit seigneur Ladislas André, curé de Brest, une cassette qui lui appartenait et où se trouvaient plusieurs privilèges, fut apportée au seigneur roi Ladislas; le roi Ladislas prit alors un de ces privilèges et dit que c'était celui par lequel les Croisés détenaient et possédaient la terre de Culm, à savoir qu'aussitôt qu'ils pourraient acquérir quelque chose au-delà de l'Ossa aux dépens des Prutènes et des Lituaniens, ils étaient tenus de restituer la dite terre de Culm aux héritiers ou aux successeurs de ce duc (...). Interrogé sur le point de savoir quel était celui qui avait concédé cette terre aux Croisés, il dit que c'était ou bien Conrad, l'aïeul du dit seigneur roi Ladislas, ou bien le duc Casimir, père de ce même seigneur Ladislas qui fut jadis roi. Interrogé sur le point de savoir quand il vit ce privilège, il dit que cela faisait environ 40 années. » 96

Pierre de Sandomir fait référence à un épisode des débuts du règne de Ladislas Łokietek, datant environ de 1299-1300. L'homme fut scribe à la cour royale et figure parmi les témoins du procès de 1321. Il est impossible de déterminer à quel diplôme il fait allusion. Selon lui s'y trouvait la promesse de restitution du Culmerland sitôt acquis un territoire en Prusse, ce qui constitue

\footnotetext{
95 Wanco figurait parmi les témoins du procès de 1321. Il conclut une alliance avec l'Ordre le 2 janvier 1326 (Pr. UB, II, $\mathrm{n}^{\circ}$ 541) et, le 29 mars 1329, accepta l'arbitrage de Jean roi de Bohême entre lui et les Teutoniques.

96 Lites, t. I, p. 378.
} 
l'idée centrale admise par l'immense majorité des trente-deux témoins. Il est possible mais pas certain que ce privilège soit identique à celui dont parle Leszek de Leslau 97.

Quatre témoins déclarent donc avoir vu des documents attestant que la donation du Culmerland était temporaire et assujettie à un engagement de restitution. Un de ces actes était conservé dans les archives de l'Ordre - c'est celui que le grand maître Charles de Trèves aurait montré au prieur d'Elbing Nicolas, les trois autres étaient aux mains des ducs de Masovie ou du roi de Pologne. Un de ces diplômes portait le sceau du grand maître Poppo d'Osterna (témoignage de Leszek de Leslau), un autre, exhibé par Ladislas Łokietek, provenait vraisemblablement des archives Cujavie (selon le témoignage de Pierre de Sandomir il était enfermé dans une cassette appartenant à un curé de Brest), et le troisième, également en possession du roi Ladislas, émanait de l'Ordre. Peut-être le document vu par Pierre de Sandomir et Leszek de Leslau était-il le même. Enfin, Ianislas de Gniezno évoque une protestation de Conrad contre le maintien de cette terre aux mains de l'Ordre.

Les faits rapportés se situent tous entre 1299-1300 et 1336, ceux de Nicolas et Jean de Cracovie semblent dater de 1324, celui de Leszek au plus tard de 1313. Les témoignages nous renvoient donc aux années 1300-1324, c'est-àdire à une époque où l'Ordre, avant et après l'installation à Marienbourg, traversait une forte crise marquée par l'opposition entre la branche prussienne animée par le maître de Prusse Frédéric de Wildenberg et la branche impériale, qui aboutit à la déposition du grand maître Charles de Trèves (1312) obligé de se réfugier hors de Prusse98. C'est enfin l'époque du premier procès intenté par la Pologne et perdu par les Teutoniques, sans conséquence réelle toutefois.

97 Wojciech Ketrzynski pensait qu'il s'agissait d'un autre exemplaire de la protestatio, alors que Irene Ziekursch y voyait deux textes différents car l'un est appelé privilège, l'autre lettre... Aucun des deux arguments n'est convaincant.

98 Ulrich Niess, Die Anfänge des Hochmeistertums in Preussen: Karl von Trier, dans Deutscher Orden 11901990, U. Arnold éd., Lüneburg, 1997, p. 33-66. 
Mais aucun des documents conservés et à la disposition des historiens ne fait état d'une donation temporaire ou d'un engagement de restitution. Par ailleurs, les diplômes évoqués ici par les témoins n'ont pas été produits devant les juges, ce qui est pour le moins surprenant, puisqu'ils auraient donné à la partie polonaise un avantage décisif (mais l'Ordre n'a pas non plus produit les diplômes en sa possession et qui allaient pourtant dans le sens de ses intérêts). Peut-on pour autant suspecter l'honnêteté des témoins? Pas nécessairement. Il semble en effet qu'une réelle confusion ait régné dans les esprits, liée aux nombreux accords conclus dans les années 1228-1235 et au souvenir de plusieurs litiges territoriaux, dont ces accords portent la trace. Cette confusion a pu être entretenue par la lecture de la Chronique de Pologne de Boguphal de Poznan, qui fait état d'une première donation temporaire, et que l'un des témoins paraît avoir lu.

Les accords de 1235 conclus entre l'Ordre et Conrad, ou ceux de 1254 passés entre le fils de Conrad, Casimir de Cujavie et le grand maître Poppo d'Osterna, ont peut-être été produits devant les témoins de 1339. Or, s'ils ne portent aucunement la trace d'une donation temporaire, ils mettent fin à des conflits territoriaux, et confirment que les terres détenues par l'Ordre l'étaient à titre perpétuel, ce qui pouvait faire croire que tel n'était pas le cas auparavant, sans que l'on puisse affirmer que cette erreur de lecture ait été ou non intentionnelle. Ainsi la lettre de protestation de Conrad de Masovie n'est pas nécessairement une fiction inventée par l'archevêque de Gniezno. Mais Conrad, qui s'opposa effectivement aux ambitions territoriales de l'Ordre en 1235, ne cherchait pas à récupérer le Culmerland : le conflit portait pour l'essentiel sur la terre de Dobrin et la protestation ne devait concerner que cette terre, non le Culmerland.

Il est par ailleurs frappant que la mémoire des témoins, pourtant souvent imprécise, est capable de remonter à des temps très anciens, antérieurs à l'arrivée des Teutoniques, puisque certains se souviennent qu'alors le 
Culmerland appartenait à la Pologne et relevait de l'Eglise de Gniezno. Dès lors, tout semble s'enchevêtrer, se confondre, plus ou moins volontairement, pour produire une nouvelle version des faits, un scénario cohérent - mais en contradiction avec les textes de nos jours disponibles - scénario qui a en 1339 le mérite de servir parfaitement les objectifs de récupération territoriale poursuivis par Casimir III. En somme, l'existence de ces contestations et de ces conflits territoriaux a pu faire naître l'idée que les donations de Conrad n'avaient été que provisoires, ce qui, au vu des diplômes conservés, ne fut plus le cas dès 1230. Il est donc probable que la mémoire polonaise associa l'éphémère caractère temporaire des années 1228-1230 aux différents litiges territoriaux, et à son propre désir de reconstituer le royaume dans ses frontières anciennes du temps de l'unité perdue - depuis le partage de 1138 ! - pour bâtir le scénario d'une usurpation de l'Ordre.

\section{Conclusion : Histoire, mémoire et idéologie}

Un siècle après le procès de Varsovie, le grand historien polonais Jan Długosz se fit l'écho des témoignages que nous venons de voir. Il présenta la donation de la terre de Culm comme provisoire et conditionnelle : l'Ordre devait la restituer entièrement une fois la conquête de la Prusse réalisée ; en outre, les Teutoniques devaient laisser au duc et à ses héritiers la moitié des terres conquises en Prusse99:

\footnotetext{
99 «Lors de cette donation des terres de Culm et de Löbau aux frères Croisés (fratres Cruciferis) par Conrad duc de Masovie et de Cujavie, une première et principale précaution avait été, que tant le maître Hermann que les frères Croisés s'étaient engagés à respecter par des lettres patentes : la possession de la terre des Prutènes et de toute autre terre soumise aux barbares qui serait conquise à l'avenir, devait être partagée à parts égales entre le duc Conrad, ses fils et les princes Polonais successeurs d'une part, et le maître et l'Ordre des Croisés d'autre part ; une fois la terre des Prutènes conquise, la donation des terres de Culm et de Löbau serait annulée, et ces terres reviendraient de plein droit au duc Conrad et à ses successeurs. », Annales seu cronicae..., Livre VI, T. 3, Varsovie, 1973, p. 258
} 
«Ce règlement lui-même et les conditions qui l'accompagnaient furent confirmés par des lettres écrites et furent très souvent examinés et discutés par certains hommes dignes de foi, auprès des ducs de Płock et de leur chancellerie. » 100

Nul doute que Długosz, qui a fait restaurer le manuscrit des actes de 1339, y ait puisé l'essentiel de ses informations. La mémoire polonaise fut, du XIIIe au XVe siècle, structurée par la double idée de la faute politique du duc Conrad, et de l'usurpation commise par l'Ordre101.

Les documents du procès ont servi à maintes reprises, lorsque la Pologne et les Teutoniques s'affrontèrent aux XIVe et XVe siècles. Les juristes y puisèrent des arguments et le champion de la cause polonaise lors du concile de Constance en 1412-1414, le grand lettré Paul Vladimir, sut en faire bon usage. Des extraits en furent transmis aux légats pontificaux chaque fois que le besoin s'en fit ressentir, ainsi qu'à la chancellerie impériale de Sigismond en 14121413. En 1422-1423 les actes du procès conduit par le légat Antionio Zeno furent enrichis avec des documents du procès de Varsovie (ainsi qu'avec la sentence de 1321). Une copie sur papier des actes de 1339 fut alors rédigée à l'intention du légat par deux notaires, Michel Lasocki, un clerc du diocèse de Plock, et Gabriel Antoine de Bossis, clerc milanais 102 .

100 Ordinacio quoque ipsa et condiciones ei aposite literarum apicibus fuerunt firmate, et per nonnullos fide dignos viros aput Ploczenses duces et eorum cameras vise sepius et tractate, Annales seu cronicae..., Livre VI, p. 258-259. L'idée d'une donation temporaire et conditionnelle des terres de Culm et de Nessau, qui devaient être restituées après la conquête de la Prusse figure de nouveau brièvement dans un autre passage de l'ouvrage, à l'année 1242 (ibid., Livre VII, T. IV, Varsovie, 1973, p. 35).

101 Jusqu'à une époque récente, tel était l'avis majoritaire des historiens polonais; Karol Gorski, entre autres, jugeait Conrad de Masovie coupable d'avoir introduit sans précautions un ordre militaire expansionniste aux frontières de la Pologne, (Karol Gorski, The Teutonic Order in Prussia, Mediaevalia et Humanistica, n 17, 1966; repris dans Karol Gorski, Communitas, Princeps, Corona regni. Studia selecta, Roczniki Towarzystwa Naukowego w Toruniu, Varsovie-Poznan-Torun, 1976, 133 p., p. 13-31).

102 Elle est de nos jours conservée aux archives centrales de Varsovie (Archiwum Główne Akt Dawnich w Warszawie, IV. 12.1.11); le texte sur papier n'est relié que par une simple feuille de parchemin blanc. Les folios sont écrits de manière peu soignée et hâtive, raturés et corrigés. Le manuscrit ne porte aucun signe de validation ; voir Helena Chłopocka, O protokołach..., op. cit., (note 14) p. 429. 
En dehors de cet usage politique, qui fut le plus important, de nombreuses copies partielles furent effectuées, destinées à un usage privé. La plus ancienne se trouvait dans la bibliothèque du Cardinal Zbigniew Olesnicki (1389-1455, évêque de Cracovie en 1423 et promu Cardinal en 1439). Ces copies reflètent tantôt une simple curiosité personnelle pour un événement majeur du passé, tantôt la volonté d'approfondir une culture juridique. La sentence du 15 septembre 1339, qui dresse en définitive un tableau assez complet des circonstances et du déroulement du procès, fut particulièrement à l'honneur 103 .

A partir du XIXe siècle l'histoire des procès de 1321 et 1339 devint un des morceaux de choix des historiographies polonaise et allemande. Les actes furent longtemps considérés sous un angle positiviste où les chercheurs, selon leur nationalité d'origine, cherchaient à établir la culpabilité ou l'innocence de l'Ordre. Le débat tourna souvent à la controverse, parfois violente, les enjeux scientifiques étant toujours doublés de perspectives politiques. Ainsi, la culpabilité de l'Ordre teutonique pouvait à son tour permettre d'accuser l'Allemagne wilhelminienne, avec l'espoir sous-jacent de donner un fondement historique et juridique aux revendications territoriales de la Pologne. Si toute l'entreprise de l'Ordre teutonique était criminelle, dans ce cas la Pologne devait récupérer l'ensemble de la Prusse orientale. En sens inverse, les chercheurs allemands appuyaient les revendications germaniques portant sur l'ensemble des territoires jadis possédés par les Teutoniques dans la région de Danzig, etc. Des auteurs tels que A. Seraphim ou I. Ziekursch refusèrent d'accorder quelque valeur que ce fut aux témoignages oraux contenus dans les actes, notamment parce qu'ils ne reposaient sur aucune base écrite 104 . Ils ne voulaient y voir que l'expression de la partialité polonaise. Personne n'était dupe du camp adverse,

103 On en trouve des copies à Varsovie, Berlin, Linköpping ou au Vatican, cf Helena Chlopocka, Procesy..., op. cit. (note 8) p. 60.

104 August Seraphim, Zur Frage der Urkundenfälschungen des deutschen Ordens, Forschungen zur Brandeburgischen und Preussischen Geschichte, 19, 1906, p. 1-87; Irene Ziekursch, Der Prozess zwischen König Kasimir von Polen und dem Deutschen Orden im Jahre 1339, Historische Studien, Berlin, 1934. 
comme le montre l'ironie du titre de la réponse de M. Perlbach à l'ouvrage de W. Kętrzyński (qui portait sur les conditions de l'arrivée des Teutoniques dans le Culmerland) : «Hermann de Salza et l'Ordre allemand devant le dernier jugement polonais », jouant sur le double sens possible du mot «Gericht» (jugement/tribunal) 105 .

Les débats se sont donc longtemps focalisés autour de la controverse juridique, mais cette attitude n'était pas totalement injustifiée. Si on répète souvent que 1'historien n'a pas à se faire juge du passé, l'examen scientifique des arguments juridiques des uns et des autres est néanmoins de son ressort, de même qu'il lui incombre de découvrir d'éventuelles falsifications de documents.

En Pologne, on s'intéressa aux procès en tant que source d'histoire politique ou des mentalités. Très tôt, de nombreux chercheurs (Marian Łodyński, Kazimierz Tymieniecki, J. Kawarsińska106) avaient vu dans les dépositions des témoins de 1321 et 1339 le reflet de l'idéologie du temps et s'étaient en particulier efforcés d'y découvrir les traces de l'émergence d'une conscience nationale polonaise. On pensa ensuite y lire la manifestation d'une culture orale et un moyen d'éclairer les mécanismes de la transmission des informations ou des opinions politiques ; en ce domaine Helena Chlopocka joua un rôle pionnier 107 .

105 Wojciech Kętrzyński, Der deutsche Orden und Konrad von Masovien, 1225-1235, Lemberg, 1904, 188 p.; Max Perlbach, Hermann von Salza und der Deutsche Orden im jüngsten polnischen Gericht, Zeitschrift des Westpreussischen Geschichtsvereins, 48, 1905 (le terme de « Gericht » fait allusion aux procès intentés à l'Ordre par les princes polonais aux XIVe et XVe siècles). Ces oppositions ne furent d'ailleurs pas systématiquement dommageables à la qualité de la recherche : dans leur volonté de ruiner les arguments du camp d'en face, les historiens des deux pays ont en effet rivalisé d'érudition et d'adresse dans l'exploitation des documents.

106 Marian Lodynski, Regnum Poloniae w opinii publicznej XIV wieku, Kwartalnik Historyczny, 28, 1914; Kazimierz Tymieniecki, Studia nad XIV wiekiem, I Proces polsko-krzyzacki z lat 1320-1321, Pzeglad Historiczny, 21, 1917-1918 ; J. Kawarsinska, Polska a Zakon krzyzacki w ostatnich latach panowania Wladyslawa Lokietka, Lwow, 1929.

107 Helena Chlopocka, Die Zeugenaussagen in den Prozessen Polens gegen den Deutschen Orden im 14. Jahrhundert, Der Deutschordenstaat Preussen in der Polnischen Geschichtsschreibung der Gegenwart, Udo Arnold et Marian Biskup éd., Marburg, 1982, p. 165-188. A la suite de ses travaux d'autres chercheurs poursuivirent des investigations sur les procès du XVe siècle (Wieslaw Sieradzan, Świadomość historyczna świadków w procesach polsko-krzyżackich w XIV I XV wieku, [la conscience historique des témoins dans les procès polono-teutonique des XIV et XVème siècles], Toruń, 1993; Andrzej Wojtkowsky, Tezy i argumenty polskie w sporach terytorialnich z krzyzakami [Thèses polonaises et arguments dans les disputes territoriales contre l'Ordre teutonique], Kommunikaty Mazursko-Warminskie, 1966, n 91, p. 3-98, 1967, n 95-96, p. 3-84 et 
En dehors des aspects de procédure qu'il permet d'analyser en détail, et qui montrent que les normes des procès pontificaux était parfaitement respectées en Europe centrale, le procès de 1339 ouvre une voie royale à l'étude de la mémoire des événements, donc à l'approche de l'opinion commune, telle du moins que l'expriment les témoins auditionnés. Le cas du Culmerland permet de voir comment une vision des faits a pu se répandre au sein de personnes qui s'affirmaient comme le porte-parole d'une vérité universellement répandue et notoire. Pourtant, seuls trente-deux témoins sur cent-vingt-six, à peine plus du quart, s'estiment en mesure d'apporter une information à ce sujet.

Il faudrait entamer une enquête systématique de tous les témoignages afin de mieux cerner l'image que l'on se faisait de l'Ordre en Pologne, en 1339, parmi les milieux hostiles aux Teutoniques. On trouverait certainement matière à de plus larges réflexions sur la construction des représentations d'un adversaire politique, en passe d'être transformé, par le biais des témoignages, en ennemi héréditaire. En effet, aux yeux des témoins les crimes et les usurpations de l'Ordre ne remontaient pas seulement à la dernière guerre, celle des années 1326-1332, mais à l'arrivée des Teutoniques sur les bords de la Vistule, plus d'un siècle auparavant. Le souvenir de la longue durée permettait de construire la figure d'un ennemi enraciné dans le passé, en un mot: ancestral ${ }^{108}$. Le procès de 1339 , et aussi celui de 1320 , sont ainsi une source importante pour appréhender la formation d'une conscience nationale polonaise, dont on perçoit les lignes de force jusque dans la deuxième moitié du XXe siècle. Décisives pour l'Ordre, en proie à une profonde crise interne, les années 1320-1339 furent aussi cruciales pour l'affirmation de l'identité polonaise. Celle-ci se forgea en serrant les rangs autour de la personne du roi et de plusieurs territoires considérés comme ayant de tout temps été polonais. Si la menace teutonique

1968, nº 99, p. 3-104.

108 Le miles Albert, officier palatin de Brest, rapporte ainsi que son père « qui était un homme âgé » et « le père de son père, homme encore plus âgé » lui ont appris que Conrad de Masovie avait donné le Culmerland aux Teutoniques pour qu'ils en chassent les païens et avec l'obligation de le restituer ensuite (Lites, t. I, p. 347). 
n'était pas encore perçue comme «allemande», s'exprimèrent cependant à Varsovie les premiers linéaments de la future idéologie du «Drang nach Osten $\gg 109$.

109 Sur la généalogie de cette vision idéologique de l’Histoire, qui fut partagée tant par les Allemands que par les Slaves, voir Wolfgang Wippermann, Der «Ddeutsche Drang nach Osten » : Ideologie und Wirklichkeit eines politischen Schlagwortes, Darmstadt, Wissenschaftliche Buchgesellschaft, 1981, VIII-153 p. 


\section{Résumés}

En 1339 se tint à Varsovie un procès opposant le royaume de Pologne à l'Ordre teutonique et présidé par des juges pontificaux. L'Ordre était accusé de crimes de guerre et sa présence sur les bords de la Vistule était dénoncée comme illégale. Les enquêteurs, après avoir auditionné cent vingt six témoins conclurent à la culpabilité des Teutoniques. L'intégralité des actes a été conservée et leur étude révèle la qualité de la procédure mise en œuvre : le procès de Varsovie a été conduit dans la stricte application des normes juridiques en vigueur dans les procès ex officio. Par ailleurs les témoignages enregistrés offrent des aperçus saisissants sur la mémoire collective. On y découvre comment l'histoire de l'arrivée des Teutoniques sur les bords de la Vistule faisait déjà l'objet de révisions historiques et de jugements contradictoires portés par la fama et soutenus par la production de documents aujourd'hui disparus. C'est finalement la fabrication d'un ennemi ancestral de la Pologne et une étape de la constitution de l'identité nationale polonaise que l'on voit se dessiner à l'occasion de ce procès.

\section{Abstract}

In 1339, a trial presided by pontifical judges at Warsaw opposed the Kingdom of Poland against the Teutonic Order. The Order was accused of crimes of war, and its presence near the Vistule was declared illegal. The investigators auditioned one hundred and twenty six witnesses and came to the conclusion that Teutonic were guilty. The whole acts have been preserved, and reveal the quality of the executed procedure. The Warsaw trial has been directed in the strict application of the juridical norms in force in the trials ex officio. By another way the collected evidences show gripping outlines about collective memory. We discover how the history of the Teutonic arrival near the Vistule was already historically reconsidered and contradictorily judged by the fama. 
These judgments were defended by a production of documents now missing. Through this trial, we finally see the making of an ancestral enemy of Poland, and a stage in the formation of the Polish national identity.

\section{Notice bio-bibliographique}

Sylvain Gouguenheim, actuellement Professeur d'Histoire Médiévale à l'ENS-LSH de Lyon consacre ses recherches à l'histoire de l'Ordre teutonique et des relations entre les ordres militaires et la Papauté. Il vient de publier Les Chevaliers Teutoniques, Paris Tallandier, 2007, 770 p. et Aristote au MontSaint-Michel; les racines grecques de l'Europe chrétienne, Paris, Seuil, 2008, $240 \mathrm{p}$.

\section{Mots-clés :}

Ordre teutonique, Pologne, Procès politique, Fama, Papauté Teutonic Order, Poland, Political Trial, Fama, Papacy 